\title{
Experimental and modeling studies of binary organic eutectic systems to be used as stabilizers for nitrate esters-based energetic materials
}

\author{
Salim Chelouche ${ }^{a, * *}$, Djalal Trache ${ }^{a,}{ }^{*}$, Simão P. Pinho ${ }^{\text {b, c }}$, Kamel Khimeche ${ }^{a}$ \\ ${ }^{\text {a } U E R ~ P r o c e ́ d e ́ s ~ E n e r g e ́ t i q u e s, ~ E c o l e ~ M i l i t a i r e ~ P o l y t e c h n i q u e, ~ E M P, ~ B P ~} 17$ Bordj-El-Bahri, 16046, Algiers, Algeria \\ ${ }^{\mathrm{b}}$ Associate Laboratory LSRE-LCM, Instituto Politécnico de Bragança, Campus de Santa Apolónia, 5300-253, Bragança, Portugal \\ ${ }^{\text {c } C e n t r o ~ d e ~ I n v e s t i g a c ̧ a ̃ o ~ d e ~ M o n t a n h a ~(C I M O), ~ I n s t i t u t o ~ P o l i t e ́ c n i c o ~ d e ~ B r a g a n c ̧ a, ~ C a m p u s ~ d e ~ S a n t a ~ A p o l o ́ n i a, ~ 5300-253, ~ B r a g a n c ̧ a, ~ P o r t u g a l ~}$
}

\section{A R T I C L E I N F O}

\section{Article history:}

Received 1 February 2019

Received in revised form

11 June 2019

Accepted 25 June 2019

Available online 28 June 2019

\section{Keywords:}

Propellant stability

Eutectic

Solid-liquid equilibrium

Modeling

Excess thermodynamic properties XRD

\begin{abstract}
A B S T R A C T
Four binary mixtures with potential for stabilizing energetic materials have been investigated. The phase diagrams of $\mathrm{N}$-(2-methoxyethyl)-p-nitroaniline + diphenylamine, $\mathrm{N}$-(2-methoxyethyl)-p-nitroaniline $+\mathrm{N}$ (2-acetoxyethyl)-p-nitroaniline, $\mathrm{N}$-(2-methoxyethyl)-p-nitroaniline +2 -nitrodiphenylamine, and $\mathrm{N}-(2$ methoxyethyl)-p-nitroaniline $+1,3$-diethyl-1,3-diphenylurea have been determined by differential scanning calorimetry. All systems display a simple eutectic behavior. Consistency tests have been applied to inspect the quality of the SLE data, showing very satisfactory quality factors. The SLE data have also been correlated by Wilson and NRTL models. The employed equations calculated the equilibrium temperatures with a root mean square deviations varying from 1.37 to $2.29 \mathrm{~K}$. These models have been applied to compute the excess thermodynamic functions as well, giving highly comparable values for a further qualitative and quantitative analysis. The results show a positive deviation from ideality for all the investigated systems due to the dominant effect of the self-association molecules. The XRD studies revealed the existence of weak interactions between the components in the formed eutectics and suggested that they are mechanical systems.
\end{abstract}

() 2019 Elsevier B.V. All rights reserved.

\section{Introduction}

Energetic materials are widely used for military as well as for civilian purposes. In the military field, one of the most important applications is to guarantee safe and efficient propulsion of different types of ammunition. These materials must maintain their performance during use and even if a long period of storage is expected. Indeed, these materials are assumed to be preserved in bulk (prior to filling) or in weapon systems for a long time under field conditions, and so a basic requirement of such formulations is their stability under various circumstances $[1,2]$. Thus, particular attention must be given to the stability of these propulsion systems which involves designing, developing, manufacturing and storing.

Nitrate ester based energetic materials such as nitrocellulose, nitroglycerine, triethylene glycol dinitrate (EGDN), 1,2-propylene glycol dinitrate (PGDN), pentaerythritol tetranitrate (PETN), are

\footnotetext{
* Corresponding author.

** Corresponding author.

E-mail addresses: salim.chelouche@gmail.com (S. Chelouche), djalaltrache@ gmail.com (D. Trache).
}

widely employed as main ingredients of propulsion systems [3]. However, the low bonding energy of the nitric ester group [2] can initiate, even at ambient temperatures, thermal decomposition of these nitrate esters, generating nitrogen oxides and other products. If not removed these latter react catalytically to accelerate the nitrate ester's degradation leading to self-ignition which may cause several disasters. To deal with this risky situation, stabilizers are commonly added to improve the stability and the shelf-life of these energetic materials.

Depending on the type of material, aromatic amines and urea derivatives are the most employed stabilizers [1]. Despite their confirmed stabilizing potential, both types produce toxic and/or potentially carcinogenic species at some point during the propellant's lifetime [4]. Many research works have been carried out trying to replace these conventional stabilizers by new emergent products [1]. However, the substitution of these so-called conventional stabilizers was found to be unsuccessful because of the limited stabilizing potential of the emergent stabilizers compared to the conventional ones. Furthermore, their impact on the environment and human health, in almost all cases, is not investigated yet. Having this in mind, the reduction of the amount of 
conventional stabilizers in the energetic materials formulations by the use of a mixture of stabilizers could be an efficient alternative.

Due to their interesting thermal and microstructural properties, organic eutectics have been successfully tested as effective phase change materials for building applications [5], as green and sustainable media, as well as catalysts in many chemical processes [6]. More specifically in the framework of this work, organic eutectics may act as blend materials and therefore, the possible incorporation of these mixtures requires an in-depth investigation. The thermodynamic analysis and the interactions studies within this kind of mixtures are very scarce. Moreover, information about the interactions occurring in a mixture of two stabilizers intended to be added to an energetic formulation is very scarce $[7,8]$. The thermodynamic investigation and the determination of the molecular interactions occurring between the compounds of a mixture of stabilizers remain a key factor to understand stability and/or compatibility issues.

In this work, phase equilibria and molecular interaction investigations have been performed by differential scanning calorimetry (DSC) and X-ray diffraction (XRD) for four binary mixtures of organic stabilizers, namely, S1: N-(2-methoxyethyl)-pnitroaniline + diphenylamine, S2: N-(2-methoxyethyl)-pnitroaniline $+\mathrm{N}$-(2-acetoxyethyl)-p-nitroaniline, S3: $\mathrm{N}-(2-$ methoxyethyl)-p-nitroaniline + 2-nitrodiphenylamine, and S4: N(2-methoxyethyl)-p-nitroaniline + 1,3-diethyl-1,3-diphenylurea (ethyl centralite). Two local compositions models, namely Wilson and NRTL have been used to calculate the solute activity coefficients and to correlate the SLE data. These equations have been employed to compute excess thermodynamic functions as well, contributing to the understanding of the type of interactions between stabilizers in the mixtures. In addition, XRD analysis had been performed to determine the intensity of the molecular interactions between the components of the mixtures.

\section{Experimental and methods}

\subsection{Materials}

Fig. 1 shows the chemical structures of the investigated components. The experimental procedure reported in the work by Gibson [9] was carefully followed for the synthesis and the purification of both N-(2-methoxyethyl)-p-nitroaniline (MENA) and $\mathrm{N}$ (2-acetoxyethyl)-p-nitroaniline (ANA). Their purities, estimated to be greater than 98 (wt.\%), were checked by DSC, FTIR, and NMR. For the newly synthesized compounds MENA and ANA, DSC thermograms, FTIR spectra, as well as ${ }^{1} \mathrm{H}$ and ${ }^{13} \mathrm{C}$ NMR spectra were acquired and are given as SM (Figs. S1-S7).

The diphenylamine (DPA) was supplied by Merck whereas both 2-nitrodiphenylamine (2-N-DPA) and 1,3-diethyl-1,3-diphenylurea (EC) were provided by Sigma-Aldrich, their mass purities were evaluated to be greater than 99 (wt.\%) according to the manufacturer's certificate. Table 1 presents the source and the purity of the studied stabilizers.

The melting properties of the pure compounds have been measured by DSC at three different heating rate, viz, 0.5, 1 and 2 $\mathrm{K} \mathrm{min}^{-1}$. The data have been used to extrapolate the melting properties values to $\beta=0 \mathrm{~K} \mathrm{~min}^{-1}$ heating rate. As shown in the recent compilation by Acree and Chickos [10], the obtained experimental data, as well as those available in the literature, are listed in Table 2 . The melting properties values are found generally in good agreement with the published data [7,9,11-18]. Concerning MENA, the enthalpy of melting was compared to those calculated by estimating methods $[19,20]$, showing to be very uniform. The accurate determination of these properties is crucial to accurately evaluate the activity coefficients as well as the thermodynamic modeling. Furthermore, Eq. (1) has been used to compute the molar volumes, whose obtained values are given in Table 2 .

$V_{\mathrm{M}}=\frac{M}{\rho}$

where $M$ stands for the molar mass $\left(\mathrm{g} \cdot \mathrm{mol}^{-1}\right)$ and $\rho$ denotes the density $\left(\mathrm{g} \cdot \mathrm{cm}^{-3}\right)$ measured at $298.15 \mathrm{~K}$ as will be described below. Excepting DPA [21] and EC [22], no experimental data were possible to find for the molar volume. Thus, estimating methods were applied for the other compounds [23], showing a good agreement with the values obtained in this study.

\subsection{Apparatus and methods}

A set of solid binary mixtures have been first prepared. A safe and precise procedure was followed in the preparation of our binary systems. Each mixture, prepared with known quantities of each component, is placed in a Pyrex glass test tube and kept airtight. The solids are gradually mixed and heated until $15 \mathrm{~K}$ above the melting point of the compound with the highest melting temperature. In order to ensure a homogeneous mixture, fast and regular stirring is recommended once the first droplets appear. Afterward, the mixture is allowed to cool down to ambient temperature. Using an agate mortar, the obtained powdered solid is stored in desiccators. It should be noticed that each sample has undergone a drying process and kept in a desiccator to avoid moisture adsorption before being analyzed.

A PerkinElmer DSC8000 was used to perform the thermal analysis. DSC device was calibrated by certified standard materials as required by the manufacturer (PerkinElmer) in the device user's manual. First, high pure indium and lead were used for the calibration procedure. This latter was subsequently confirmed by analyzing with zinc. The accuracy of the calibration procedure is found to be equal to $\pm 0.1 \mathrm{~K}$ for the temperature of melting and did not exceed $2 \%$ for the enthalpy of melting. For each measurement, 5-6 mg of the mixture was weighed using a Mettler H31 balance, (precision $\pm 0.00002 \mathrm{~g}$ ) and charged to aluminum crucibles. Indeed, the employed reference consisted of the same empty pan.

The prepared mixtures must be homogenous and uniform. For that, a specific procedure was followed which first involves a heating cycle of the sample until $15 \mathrm{~K}$ above the melting point of the compound with the highest melting temperature. The sample is kept at that temperature for $20 \mathrm{~min}$, then cooled down to room temperature and kept in this state for $20 \mathrm{~min}$. Second heating is then performed under a nitrogen atmosphere $\left(20 \mathrm{~cm}^{3} \mathrm{~min}^{-1}\right)$ in the temperature range of $300-400 \mathrm{~K}$ for S1, S3 and, S4 and of $320-400 \mathrm{~K}$ for $\mathrm{S} 2$, at a heating rate of $2 \mathrm{~K} \mathrm{~min}^{-1}$. This slow scanning rate is chosen to approach the equilibrium measurement conditions [11] and to further improve the correctness of the melting enthalpy evaluation. Some selected mixtures have been tested under different heating/cooling rates and isothermal periods. The change in the operating conditions results in similar DSC thermograms without the appearance of unexpected thermal phenomena which confirms that the DSC procedure followed in this work guarantees the quality and the precision of the data.

PerkinElmer's Pyris software was used to determine the melting properties of our investigated samples. Moreover, measurement uncertainties associated with the mole fraction, the temperature, and the enthalpy of melting were found to be equal to \pm 0.0005 , $\pm 0.4 \mathrm{~K}$, and $\pm 0.4 \mathrm{~kJ} \mathrm{~mol}^{-1}$, respectively. 
<smiles>COCCNc1ccc([N+](=O)[O-])cc1</smiles>

(a)

(d)<smiles>CCN(C(=O)N(CC)c1ccccc1)c1ccccc1</smiles><smiles>c1ccc(Nc2ccccc2)cc1</smiles>

(b)<smiles>CC(=O)OCCNc1ccc([N+](=O)[O-])cc1</smiles>

(c)

(e)

Fig. 1. Chemical structure of the studied compounds: (a) N-(2-methoxyethyl)-p-nitroaniline (MENA); (b) Diphenylamine (DPA); (c) N-(2-acetoxyethyl)-p-nitroaniline (ANA); (d) 2nitrodiphenylamine (2-N-DPA); (e) 1,3-diethyl-1,3-diphenylurea (EC).

Table 1

Designation of the studied stabilizers: Source, purification method, and final mass fraction purity.

\begin{tabular}{|c|c|c|c|c|c|}
\hline Chemical name & Source & $\begin{array}{l}\text { Initial mass } \\
\text { fraction purity }\end{array}$ & Purification method & $\begin{array}{l}\text { Final mass } \\
\text { fraction purity }\end{array}$ & $\begin{array}{l}\text { Analysis } \\
\text { method }\end{array}$ \\
\hline N-(2-methoxyethyl)-p-nitroaniline (MENA) & Laboratory Synthesis & - & Filtration + Repeated crystallization & 0.98 & $\begin{array}{l}\text { NMR }^{\mathrm{a}} \\
\text { FTIR }^{\mathrm{b}} \\
\text { DSC }^{\mathrm{c}}\end{array}$ \\
\hline Diphenylamine (DPA) & Merck & 0.99 & - & - & - \\
\hline $\mathrm{N}$-(2-acetoxyethyl)-p-nitroaniline(ANA) & Laboratory Synthesis & - & Filtration + Repeated crystallization & 0.98 & $\begin{array}{l}\text { NMR }^{\mathrm{a}} \\
\text { FTIR }^{\mathrm{b}} \\
\text { DSC }^{\mathrm{c}}\end{array}$ \\
\hline 2-Nitrodiphenylamine (2-N-DPA) & Sigma-Aldrich & 0.99 & - & - & - \\
\hline 1,3-diethyl-1,3-diphenylurea (EC) & Sigma-Aldrich & 0.99 & - & - & - \\
\hline
\end{tabular}

a Nuclear magnetic resonance spectroscopy.

b Fourier transform infrared.

c Differential scanning calorimeter.

As recommended and very often used by several authors [24-27], melting temperatures for both pure compounds and eutectics, are determined from the onset temperature of the melting peak. However, as far as we know, no specific recommendation exists for binary mixtures until now.

Furthermore, liquidus is defined as the disappearance of the last crystals in the liquid phase, hence, onset temperatures are not suitable. The determination of the liquidus temperatures is not obvious, which can be supported by the number of approaches employed by the authors. Onset temperature has been considered in some studies as $T_{\text {liquidus }}$ despite the qualitatively different nature of melting in a mixture to that in a pure compound [28].

Other studies have identified $T_{\text {liquidus }}$ as the peak top temperature. Nevertheless, it has been verified that this top peak does not represent the point of complete dissolution but defines, more exactly, the point where the energy exchange between the sample and thermocouples is at a maximum $[28,29]$. Some other studies have adopted numerical post-experiment methodologies based on factors influencing the shape of the thermogram to identify $T_{\text {liquidus }}$ $[30,31]$. Still that all these procedures are under development and limited by several factors [28].

Recently, Oakley et al. [28] have established a robust and simple way of identifying $T_{\text {liquidus }}$ in hydrocarbon mixtures which leads to consistent liquidus temperature data. The method presents the endset as being the point which best describes the complete dissolution of the mixture and therefore the point to be taken as $T_{\text {liquidus. }}$

The endset temperature is chosen in this work to be assigned to the liquidus temperature of the organic binary mixtures under study. Differences between onset and endset temperatures for pure compounds and eutectics have been evaluated (Table 3 ) and found to not exceed $2.3 \mathrm{~K}$, validating the choice of the endset as liquidus temperature. The onset temperature is derived from the intersection between the tangent to the maximum rising slope upon fusion, 
Table 2

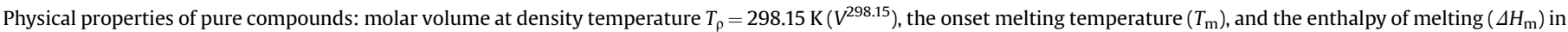
the DSC experiments, at $\mathrm{p}=0.1 \mathrm{MPa}$.

\begin{tabular}{|c|c|c|c|c|c|c|c|c|c|c|c|c|}
\hline \multirow[t]{3}{*}{ Compound } & \multicolumn{3}{|l|}{ literature } & \multicolumn{3}{|l|}{ This work } & & & & & & \\
\hline & \multirow{2}{*}{$\begin{array}{l}V \\
\left(\mathrm{~cm}^{3} \cdot \mathrm{mol}^{-1}\right)\end{array}$} & \multirow[t]{2}{*}{$T_{\mathrm{m}}(\mathrm{K})$} & \multirow{2}{*}{$\begin{array}{l}\Delta H_{\mathrm{m}} \\
\left(\mathrm{kJ} \cdot \mathrm{mol}^{-1}\right)\end{array}$} & \multirow{2}{*}{$\begin{array}{l}V^{\mathrm{g}} \\
\left(\mathrm{cm}^{3} \cdot \mathrm{mol}^{-1}\right)\end{array}$} & \multicolumn{2}{|c|}{$\beta=2 \mathrm{~K} \cdot \mathrm{min}^{-1}$} & \multicolumn{2}{|c|}{$\beta=1 \mathrm{~K} \cdot \mathrm{min}^{-1}$} & \multicolumn{2}{|c|}{$\beta=0.5 \mathrm{~K} \cdot \mathrm{min}^{-1}$} & \multicolumn{2}{|c|}{$\beta=0 \mathrm{~K} \cdot \mathrm{min}^{-1}$} \\
\hline & & & & & $T_{\mathrm{m}}^{\mathrm{h}}(\mathrm{K})$ & $\begin{array}{l}\Delta H_{\mathrm{m}} \\
\left(\mathrm{kJ} \cdot \mathrm{mol}^{-1}\right)\end{array}$ & $T_{\mathrm{m}}^{\mathrm{h}}(\mathrm{K})$ & $\begin{array}{l}\Delta H_{\mathrm{m}} \\
\left(\mathrm{kJ} \cdot \mathrm{mol}^{-1}\right)\end{array}$ & $T_{\mathrm{m}}^{\mathrm{h}}(\mathrm{K})$ & $\begin{array}{l}\Delta H_{\mathrm{m}} \\
\left(\mathrm{kJ} \cdot \mathrm{mol}^{-1}\right)\end{array}$ & $T_{\mathrm{m}}^{\mathrm{h}}(\mathrm{K})$ & $\begin{array}{l}\Delta H_{\mathrm{m}} \\
\left(\mathrm{kJ} \cdot \mathrm{mol}^{-1}\right)\end{array}$ \\
\hline \multirow{2}{*}{$\begin{array}{l}\text { N-(2-methoxyethyl)- } \\
\text { p-nitroaniline (MENA) }\end{array}$} & 154.1a & 356.15-359.15 [9] & 25.9 [19] & \multirow[t]{2}{*}{152.7} & \multirow[t]{2}{*}{358.9} & \multirow[t]{2}{*}{27.3} & \multirow[t]{2}{*}{358.4} & \multirow[t]{2}{*}{26.9} & \multirow[t]{2}{*}{358.1} & \multirow[t]{2}{*}{26.2} & \multirow[t]{2}{*}{357.9} & \multirow[t]{2}{*}{26.0} \\
\hline & $151.4^{\mathrm{b}}$ & & $24.4[20]$ & & & & & & & & & \\
\hline \multirow[t]{5}{*}{ Diphenylamine (DPA) } & $145.9[21]$ & $326.6^{c}[11]$ & $19.7[11]$ & \multirow[t]{5}{*}{144.8} & \multirow[t]{5}{*}{325.6} & \multirow[t]{5}{*}{19.5} & \multirow[t]{5}{*}{325.1} & \multirow[t]{5}{*}{19.3} & \multirow[t]{5}{*}{324.9} & \multirow[t]{5}{*}{19.0} & \multirow[t]{5}{*}{324.6} & \multirow[t]{5}{*}{18.9} \\
\hline & $142.4^{\mathrm{a}}$ & $326.15[12]$ & $17.86[12]$ & & & & & & & & & \\
\hline & & $325.1[13]$ & $18.5[14]$ & & & & & & & & & \\
\hline & & $326.3[14]$ & $19.9[15]$ & & & & & & & & & \\
\hline & & $326.1[15]$ & & & & & & & & & & \\
\hline \multirow{3}{*}{$\begin{array}{l}\mathrm{N}-(2 \text {-acetoxyethyl)-p } \\
\text {-nitroaniline (ANA) }\end{array}$} & $169.4^{\mathrm{a}}$ & $387.4^{\mathrm{c}}[16]$ & \multirow[t]{3}{*}{$26.1[7]$} & \multirow[t]{3}{*}{169.2} & 386.3 & 20.7 & 385.9 & 20.4 & 385.5 & 20.1 & 385.2 & 20.0 \\
\hline & $168.6^{\mathrm{b}}$ & $387.0^{c}[11]$ & & & & & & & & & & \\
\hline & & $388.15-392.15$ [9] & & & & & & & & & & \\
\hline 2-Nitrodiphenylamine & $161.06^{\mathrm{b}}$ & $347.94^{\mathrm{d}, \mathrm{e}}[7]$ & $26.1^{\mathrm{d}}[7]$ & 158.6 & 347.9 & 23.2 & 347.4 & 22.8 & 347.1 & 22.2 & 346.9 & 22.0 \\
\hline$(2-\mathrm{N}-\mathrm{DPA})$ & & $346.15[17]$ & & & & & & & & & & \\
\hline 1,3-diethyl-1,3- & $230.4^{\mathrm{a}}$ & 346.15 [17] & $29.6[18]$ & 242.0 & 345.7 & 29.5 & 345.3 & 28.9 & 345.1 & 28.2 & 344.9 & 28.0 \\
\hline diphenylurea (EC) & 241.36 [22] & $343.3^{\mathrm{f}}[18]$ & & & & & & & & & & \\
\hline
\end{tabular}

Standard uncertainties u are: $u(V)= \pm 0.4 \mathrm{~cm}^{3} \mathrm{~mol}^{-1}, u\left(T_{\mathrm{m}}\right)= \pm 0.4 \mathrm{~K}, u\left(\Delta H_{\mathrm{m}}\right)= \pm 0.4 \mathrm{~kJ} \mathrm{~mol}^{-1}, u\left(T_{\rho}\right)= \pm 0.06 \mathrm{~K}, u(p)=0.05 \mathrm{kPa}$.

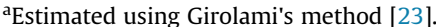

${ }^{\mathrm{b}}$ Estimated using Imerizi's method [23].

${ }^{c}$ Peak top temperature.

${ }^{d}$ At $\beta=2 \mathrm{Kmin}^{-1}$.

e Peak top temperature.

${ }^{\mathrm{f}}$ At $\beta=20 \mathrm{Kmin}^{-1}$.

${ }^{\mathrm{g}}$ Measured for crystals at $T=298.15 \mathrm{~K}$.

${ }^{\mathrm{h}}$ Onset temperature.

Table 3

Differences between onset and endset temperatures for pure components and eutectics.

\begin{tabular}{llll}
\hline & $T^{\mathrm{a}}{ }_{\text {onset }}(\mathrm{K})$ & $T^{\mathrm{a}}{ }_{\text {endset }}(\mathrm{K})$ & $\Delta T(\mathrm{~K})$ \\
\hline MENA & 358.9 & 361.1 & 2.2 \\
DPA & 325.6 & 329.9 & 1.3 \\
ANA & 386.3 & 388.4 & 2.1 \\
2-N-DPA & 347.9 & 349.8 & 1.9 \\
EC & 345.7 & 347.2 & 1.5 \\
MENA + DPA & 313.7 & 315.8 & 2.1 \\
MENA + ANA & 345.1 & 347.4 & 2.3 \\
MENA+2-N-DPA & 332.0 & 334.3 & 2.3 \\
MENA + EC & 328.2 & 330.2 & 2.0 \\
\hline
\end{tabular}

a At $\beta=2 \mathrm{Kmin}^{-1}$

and the baseline curve, while the endset temperature is obtained following the same concept by exploring the right part of the peak.

A helium gas pycnometer (Micromeritics, AccuPyc II 1340) was used to evaluate the densities of the pure compounds. The volume of the five stabilizers is measured by replacing their void space with helium. Independent and simultaneous measurements of the mass were performed in prior in order to determine the density. Three tests were made for each sample, where each one consisted of 10 measurement cycles. Uncertainties were assessed to be less than $\pm 0.003 \mathrm{~g} \mathrm{~cm}^{-3}$, whereas the temperature uncertainty was estimated to be lower than $\pm 0.06 \mathrm{~K}$.

The X-ray diffraction analysis was carried out to bring out the crystal structure of both pure substances and eutectics. Such a method allows the assessment of eventual changes in the crystal structure. PANanlytical X'Pert ProMulti-Purpose Diffractometer with $\mathrm{Cu} \mathrm{K} \alpha$ radiation was employed to perform the measurements at ambient temperature. An X'Celerator detector was utilized to collect data over an angular range of $10-30^{\circ} / 2 \theta$, with a step size of $0.0170 / 2 \theta$ and a count time of 50.1650 s at each step.

\section{Results and discussion}

\subsection{Solid-liquid equilibria}

\subsubsection{Solid-liquid phase diagrams}

Plots (a) to (d) reported in Fig. 2 present the DSC thermograms for the different prepared fractions of the four investigated systems $\operatorname{MENA}(1)+\operatorname{DPA}(2), \operatorname{MENA}(1)+\operatorname{ANA}(2), \operatorname{MENA}(1)+2-\mathrm{N}-\mathrm{DPA}$, and MENA(1) + EC(2), respectively, while Tables 4-7 list the experimental results obtained for all systems.

The thermograms of pure compounds show one endothermic phenomenon, attributed to the fusion. However, the DSC thermograms for all the investigated binary mixtures exhibit two melting peaks. The first one corresponds to the melting of the eutectic, whereas the second, occurring at a higher temperature than that of the eutectic melting, was assigned to the mixture melting (liquidus line). From Fig. 2, it can be clearly verified that for each system, the eutectic temperature appears approximately at a constant value, while the variation in the mixture composition leads to a change in the mixture melting point. Therefore, the systems under study exhibit simple eutectic behaviors.

Using the triangle shape Tamman's plot, linear regressions of the eutectic enthalpy of melting versus the mole fraction (Fig. 3(a)-(d)) permit the estimation of the eutectic composition for S1-S4 systems as follow: $x_{1, \mathrm{eu}}=0.3129, x_{1, \mathrm{eu}}=0.6688, x_{1, \mathrm{eu}}=0.3905$, and $x_{1, \mathrm{eu}}=0.4305$, respectively.

Afterward, the four eutectics have been prepared (at the estimated composition) and then characterized by DSC. As depicted in plots (a) to (d) in Fig. 2, the thermograms corresponding to these particular compositions only present one endothermic peak. The eutectic melting temperatures obtained for S1-S4 are found to be equal to $313.7 \mathrm{~K}, 345.1 \mathrm{~K}, 332.0 \mathrm{~K}$, and $328.2 \mathrm{~K}$, respectively. Besides, the experimental enthalpies of melting of the four eutectics are found to be equal to $13.1 \mathrm{kJmol}^{-1}, 17.3 \mathrm{kJmol}^{-1}, 21.3 \mathrm{kJmol}^{-1}$, and 
(a)

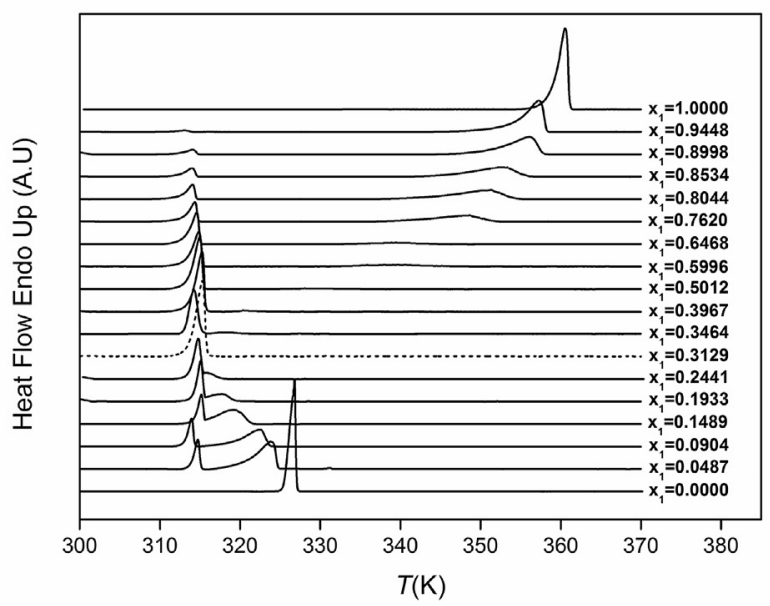

(b)

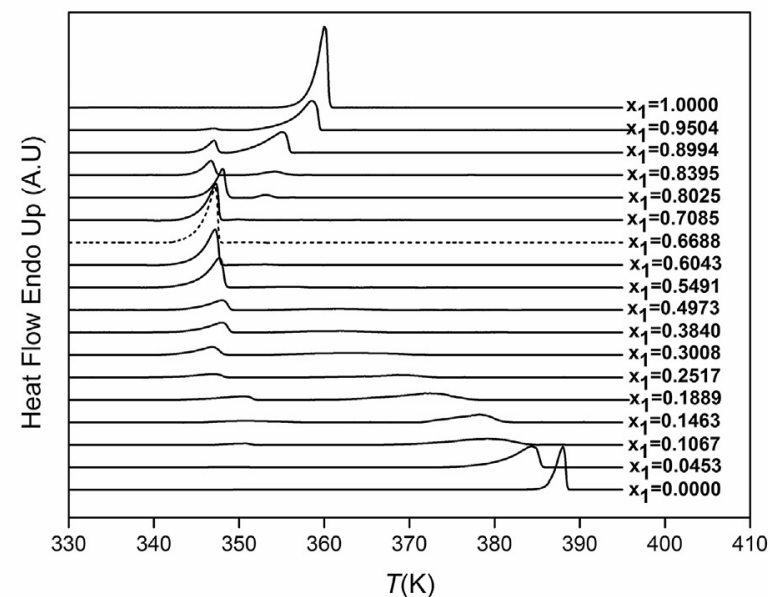

(c)

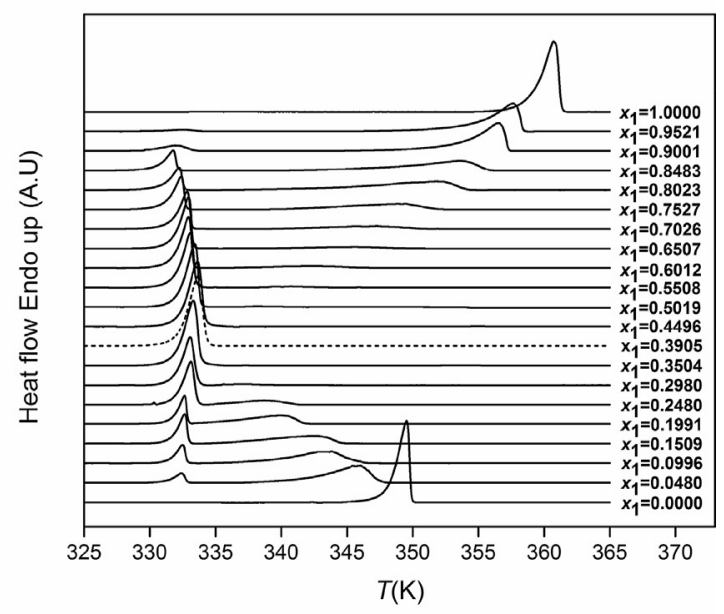

(d)

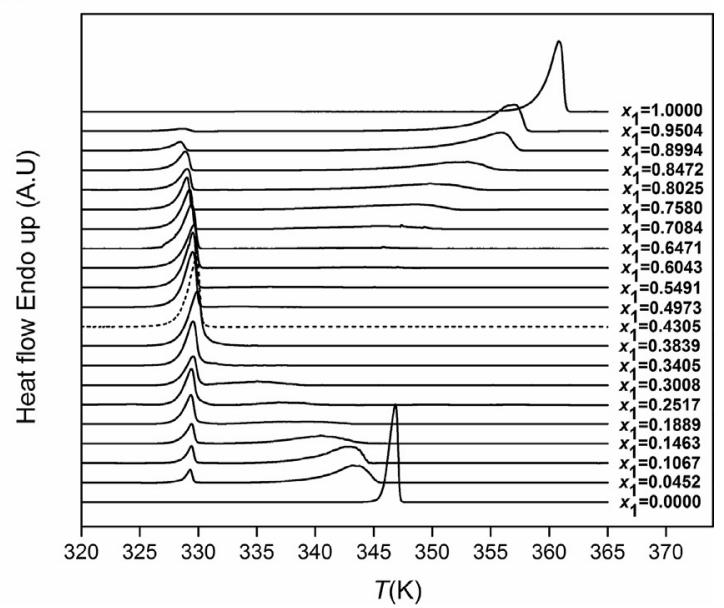

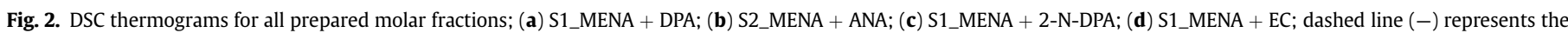
experimental eutectic fraction.

Table 4

Experimental SLE data for MENA (1) + DPA (2) system at different MENA mole fractions $\left(x_{1}\right)$ and $\mathrm{p}=0.1 \mathrm{MPa}$, displaying the liquidus temperature $\left(T_{\text {liq }}\right)$, the eutectic temperature $\left(T_{\mathrm{eu}}\right)$, the melting enthalpy at the eutectic $\left(\Delta H_{\mathrm{eu}}\right)$, and the solid phase.

\begin{tabular}{lllll}
\hline$x_{1}$ & $T_{\text {liq }}(\mathrm{K})$ & $T_{\text {eu }}(\mathrm{K})$ & $\Delta H_{\mathrm{eu}}\left(\mathrm{J} \cdot \mathrm{g}^{-1}\right)$ & Solid phase \\
\hline 0.0000 & 325.6 & - & 0.0 & DPA (cr) \\
0.0487 & 324.4 & 313.3 & 15.3 & DPA (cr) \\
0.0904 & 322.9 & 313.0 & 21.4 & DPA (cr) \\
0.1489 & 321.2 & 313.8 & 31.7 & DPA (cr) \\
0.1933 & 319.4 & 313.6 & 45.2 & DPA (cr) \\
0.2441 & 317.6 & 313.2 & 58.9 & DPA (cr) \\
0.3464 & 319.9 & 313.5 & 70.2 & MENA (cr) \\
0.3967 & 322.9 & 313.6 & 64.6 & MENA (cr) \\
0.5012 & 332.3 & 313.2 & 53.2 & MENA (cr) \\
0.5996 & 341.6 & 313.2 & 44.2 & MENA (cr) \\
0.6468 & 344.7 & 313.0 & 39.2 & MENA (cr) \\
0.7620 & 350.9 & 313.0 & 27.7 & MENA (cr) \\
0.8044 & 353.0 & 312.7 & 20.9 & MENA (cr) \\
0.8534 & 354.9 & 312.5 & 14.3 & MENA (cr) \\
0.8998 & 356.3 & 312.6 & 9.6 & MENA (cr) \\
0.9448 & 357.4 & 311.6 & 4.6 & MENA (cr) \\
1.0000 & 358.9 & - & 0.0 &
\end{tabular}

Standard uncertainties $u$ are: $u(x)= \pm 0.0005, u(T)= \pm 0.4 \mathrm{~K}, u\left(\Delta H_{\mathrm{eu}}\right)= \pm 1.9 \mathrm{Jg}^{-1}$, $u(p)=0.05 \mathrm{kPa}$
Table 5

Experimental SLE data for MENA (1) + ANA (2) system at different MENA mole fractions $\left(x_{1}\right)$ and $\mathrm{p}=0.1 \mathrm{MPa}$, displaying the liquidus temperature $\left(T_{\mathrm{liq}}\right)$, the eutectic temperature $\left(T_{\mathrm{eu}}\right)$, the melting enthalpy at the eutectic $\left(\Delta H_{\mathrm{eu}}\right)$, and the solid phase

\begin{tabular}{lllll}
\hline$x_{1}$ & $T_{\text {liq }}(\mathrm{K})$ & $T_{\text {eu }}(\mathrm{K})$ & $\Delta H_{\mathrm{eu}}\left(\mathrm{J} \cdot \mathrm{g}^{-1}\right)$ & Solid phase \\
\hline 0.0000 & 386.3 & - & 0.0 & ANA (cr) \\
0.0453 & 385.0 & 344.3 & 6.1 & ANA (cr) \\
0.1067 & 382.9 & 344.5 & 14.3 & ANA (cr) \\
0.1463 & 380.5 & 344.6 & 19.7 & ANA (cr) \\
0.1889 & 377.2 & 344.1 & 25.6 & ANA (cr) \\
0.2517 & 373.0 & 343.6 & 33.5 & ANA (cr) \\
0.3008 & 370.5 & 343.8 & 40.0 & ANA (cr) \\
0.3840 & 366.6 & 343.9 & 46.7 & ANA (cr) \\
0.4973 & 359.5 & 343.9 & 60.6 & ANA (cr) \\
0.5491 & 356.4 & 344.1 & 68.3 & ANA (cr) \\
0.6043 & 351.4 & 345.0 & 76.8 & ANA (cr) \\
0.7085 & 348.8 & 344.4 & 81.3 & MENA (cr) \\
0.8025 & 353.2 & 345.1 & 55.2 & MENA (cr) \\
0.8395 & 355.2 & 345.0 & 38.8 & MENA (cr) \\
0.8994 & 356.7 & 344.8 & 21.2 & MENA (cr) \\
0.9504 & 357.8 & 344.2 & 7.3 & MENA (cr) \\
1.0000 & 358.9 & - & 0.0 & MENA (cr) \\
\hline
\end{tabular}

Standard uncertainties $u$ are: $u(x)= \pm 0.0005, u(T)= \pm 0.4 \mathrm{~K}, u\left(\Delta H_{\mathrm{eu}}\right)= \pm 1.9 \mathrm{Jg}^{-1}$, $u(p)=0.05 \mathrm{kPa}$. 
Table 6

Experimental SLE data for MENA (1) + 2-N-DPA (2) system at different MENA mole fractions $\left(x_{1}\right)$ and $\mathrm{p}=0.1 \mathrm{MPa}$, displaying the liquidus temperature $\left(T_{\mathrm{liq}}\right)$, the eutectic temperature $\left(T_{\mathrm{eu}}\right)$, the melting enthalpy at the eutectic $\left(\Delta H_{\mathrm{eu}}\right)$, and the solid phase.

\begin{tabular}{lllll}
\hline$x_{1}$ & $T_{\text {liq }}(\mathrm{K})$ & $T_{\text {eu }}(\mathrm{K})$ & $\Delta H_{\mathrm{eu}}\left(\mathrm{J} \cdot \mathrm{g}^{-1}\right)$ & Solid phase \\
\hline 0.0000 & 347.9 & - & - & $2-N-D P A(c r)$ \\
0.0480 & 347.1 & 331.2 & 10.0 & $2-N-D P A(c r)$ \\
0.0996 & 345.6 & 331.3 & 25.4 & $2-N-D P A(c r)$ \\
0.1509 & 344.3 & 331.4 & 37.4 & $2-N-D P A(c r)$ \\
0.1991 & 342.3 & 331.5 & 52.6 & $2-N-D P A(c r)$ \\
0.2480 & 340.7 & 331.7 & 64.7 & $2-N-D P A(c r)$ \\
0.2980 & 338.1 & 331.9 & 81.7 & $2-N-D P A(c r)$ \\
0.3504 & 335.5 & 331.9 & 95.4 & $2-N-D P A(c r)$ \\
0.4496 & 336.7 & 332.0 & 97.5 & MENA (cr) \\
0.5019 & 339.7 & 332.1 & 88.3 & MENA (cr) \\
0.5508 & 343.1 & 331.6 & 78.6 & MENA (cr) \\
0.6012 & 345.8 & 331.4 & 69.2 & MENA (cr) \\
0.6507 & 348.0 & 331.4 & 60.3 & MENA (cr) \\
0.7026 & 350.1 & 331.4 & 51.1 & MENA (cr) \\
0.7527 & 351.8 & 331.2 & 41.0 & MENA (cr) \\
0.8023 & 353.8 & 330.7 & 31.7 & MENA (cr) \\
0.8483 & 355.4 & 330.4 & 21.6 & MENA (cr) \\
0.9001 & 357.1 & 330.3 & 15.3 & MENA (cr) \\
0.9521 & 358.1 & 330.4 & 5.8 & MENA (cr) \\
1.0000 & 358.9 & - & - & MENA (cr) \\
\hline
\end{tabular}

Standard uncertainties $u$ are: $u(x)= \pm 0.0005, u(T)= \pm 0.4 \mathrm{~K}, u\left(\Delta H_{\mathrm{eu}}\right)= \pm 1.9 \mathrm{Jg}^{-1}$, $u(p)=0.05 \mathrm{kPa}$.

Table 7

Experimental SLE data for MENA (1) + EC (2) system at different MENA mole fractions $\left(x_{1}\right)$ and $\mathrm{p}=0.1 \mathrm{MPa}$, displaying the liquidus temperature $\left(T_{\text {liq }}\right)$, the eutectic temperature $\left(T_{\mathrm{eu}}\right)$, the melting enthalpy at the eutectic $\left(\Delta H_{\mathrm{eu}}\right)$, and the solid phase.

\begin{tabular}{lllll}
\hline$x_{1}$ & $T_{\text {liq }}(\mathrm{K})$ & $T_{\text {eu }}(\mathrm{K})$ & $\Delta H_{\mathrm{eu}}\left(\mathrm{J} \cdot \mathrm{g}^{-1}\right)$ & Solid phase \\
\hline 0.0000 & 345.7 & - & - & EC (cr) \\
0.0452 & 345.3 & 328.5 & 10.1 & EC (cr) \\
0.1067 & 344.4 & 328.3 & 20.6 & EC (cr) \\
0.1463 & 343.7 & 328.3 & 29.7 & EC (cr) \\
0.1889 & 342.7 & 328.2 & 39.8 & EC (cr) \\
0.2517 & 340.0 & 328.1 & 55.7 & EC (cr) \\
0.3008 & 337.9 & 327.9 & 65.7 & EC (cr) \\
0.3405 & 335.6 & 327.9 & 76.1 & EC (cr) \\
0.3839 & 333.1 & 328.2 & 86.2 & EC (cr) \\
0.4973 & 334.1 & 327.9 & 85.9 & MENA (cr) \\
0.5491 & 339.4 & 327.9 & 77.1 & MENA (cr) \\
0.6043 & 343.6 & 327.8 & 65.5 & MENA (cr) \\
0.6471 & 346.3 & 327.5 & 57.9 & MENA (cr) \\
0.7084 & 349.4 & 327.8 & 48.4 & MENA (cr) \\
0.7580 & 351.6 & 327.7 & 40.4 & MENA (cr) \\
0.8025 & 353.7 & 327.7 & 31.9 & MENA (cr) \\
0.8472 & 355.2 & 327.6 & 25.1 & MENA (cr) \\
0.8994 & 356.9 & 327.1 & 14.9 & MENA (cr) \\
0.9504 & 357.9 & 326.9 & 5.8 & MENA (cr) \\
1.0000 & 358.9 & - & - & MENA (cr) \\
\hline
\end{tabular}

Standard uncertainties $u$ are: $u(x)= \pm 0.0005, u(T)= \pm 0.4 \mathrm{~K}, u\left(\Delta H_{\mathrm{eu}}\right)= \pm 1.9 \mathrm{Jg}^{-1}$, $u(p)=0.05 \mathrm{kPa}$.

$22.3 \mathrm{kJmol}^{-1}$, respectively. Table 8 summarizes the obtained values for the eutectic coordinates. The uncertainties associated with each experimental eutectic coordinate are found to be very satisfactory and lower than the values reported above.

High melting temperature compared to that of storage is one of the basic requirement for stabilizers intended to be incorporated into energetic materials [1,11]. Indeed, a low melting point can provoke the fusion of the stabilizer, then its diffusion within the energetic material thus affecting the stabilizing efficiency because of the decrease of stabilizers amount. The migration of the liquid after the fusion can lead thereafter to self-ignition or unexpected explosions due to the loss of the energetic material structure integrity, the reduction of the thermal stability, and the decrease in the desired chemical, mechanical and ballistic characteristics and performances. From the obtained SLE diagrams, the system MENA(1)+DPA(2) presents relatively a low temperature if stored in hot regions, while the other three systems have high eutectic temperatures. Consequently, these eutectics can be safely added into nitrate ester based energetic materials formulations.

\subsubsection{Consistency tests}

Kang et al. [32] have proposed different consistency tests to check the quality of the phase equilibria data. These approaches are necessary for the selection of the experimental data to apply in the developing and testing of predictive and correlative models. The consistency of the data measured in this work has been assessed based on the SLE experimental data obtained for the four binary mixtures, as well as appropriate features of the pure compounds.

Based on the differences between the melting temperature and enthalpy, estimated from binary solubility data and compared to the pure component property values, a quality factor $\mathrm{Q}_{\mathrm{SLE}}$ ranging between 0 and 1 is computed. The detailed procedure can be found in the paper of Kang et al. [32] in which it is reported that a quality factor of 0.55 implied a less consistent data set. The obtained results in this work are reported in Table 9, where the quality factors are found to be excellent for S2 (0.943), good for S1 (0.859) and S3 (0.794), and acceptable for S4 (0.703). Otherwise, the divergence on the melting enthalpy is the main contribution to the decrease of the global quality factors.

\subsubsection{Modeling}

Applying the usual assumptions, the SLE curves of the binary mixtures studied in this work can be evaluated through Eq. (2) [33]:

$\ln x_{1} \gamma_{1}=-\frac{\Delta_{\mathrm{m}} H_{1}}{R}\left(\frac{1}{T}-\frac{1}{T_{\mathrm{m}, 1}}\right)+\frac{\Delta_{\mathrm{m}} C_{\mathrm{p}, 1}}{R}\left(\frac{T_{\mathrm{m}, 1}-T}{T}+\ln \frac{T}{T_{\mathrm{m}, 1}}\right)$

where $\gamma_{1}$ is the activity coefficient of compound $1, x_{1}, \Delta_{\mathrm{m}} H_{1}$, $\Delta_{\mathrm{m}} C_{\mathrm{p}, 1}$ and $T_{\mathrm{m}, 1}$ denote, respectively, the mole fraction, the enthalpy of melting, the difference in the heat capacity between liquid and solid states at the melting temperature, and the melting temperature of pure solute $1, T$ is the absolute equilibrium temperature of the binary system and $R$ is the universal gas constant. A quick reflection allows verifying that the first term on the righthand side of Eq. (2) is dominant as it was suggested by Prausnitz et al. [34]. More explicitly, the heat capacity term is usually neglected when compared to the other terms as it is generally unknown and small enough. To confirm the advanced hypothesis some calculations were performed due to the unavailability of the heat capacity values of the pure components in both liquid and solid states. In fact, testing different values for the heat capacity change upon melting, even when this value is as high as $50 \mathrm{~J} \mathrm{~mol}^{-1} \mathrm{~K}^{-1}$, the importance of the second term in the right side of Eq. (2) is always lower than $4.9 \%$, validating the proposed simplification. Moreover, the standard deviation associated with the temperature calculations taking into account the contribution of $4.9 \%$ from the second term was evaluated and found to be very small if compared to those using the semi-empirical models, confirming once again the correctness of the performed sensibility test.

Besides to the activity coefficient, excess thermodynamic functions, conveying the difference between the thermodynamic functions of a real system and that of the ideal one at the same temperature and pressure are often used to evaluate the deviation from ideal behavior and to determine the type of interactions governing the systems. In particular excess Gibbs energy $\left(G^{\mathrm{E}}\right)$, enthalpy $\left(H^{\mathrm{E}}\right)$, and entropy $\left(S^{\mathrm{E}}\right)$ are usually under attention $[35,36]$.

In this study, the computation of the solute activity coefficients 
(a)

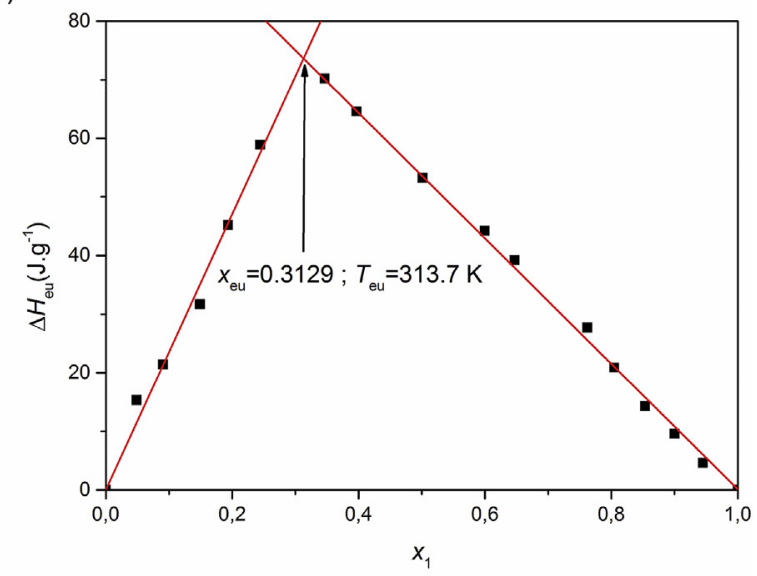

(b)

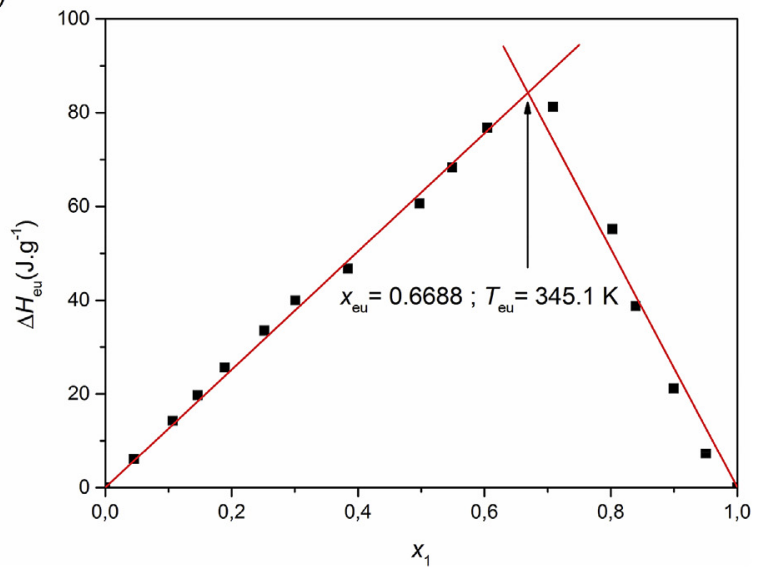

(c)

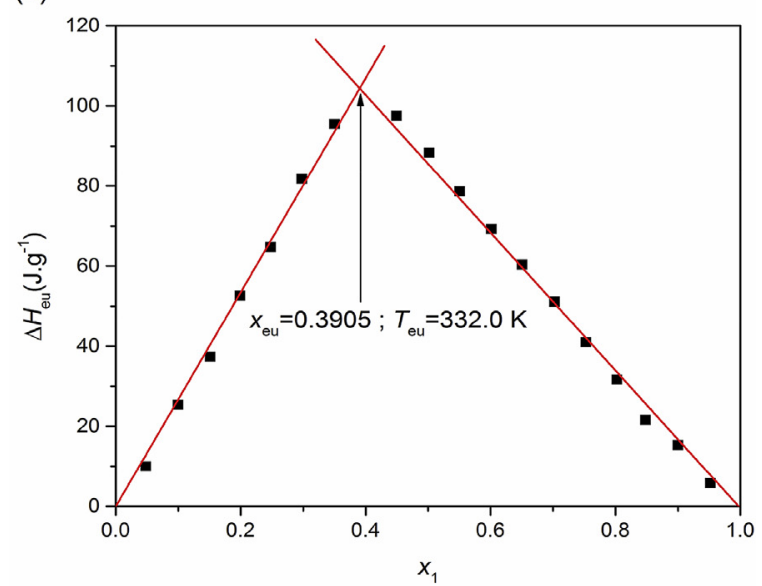

(d)

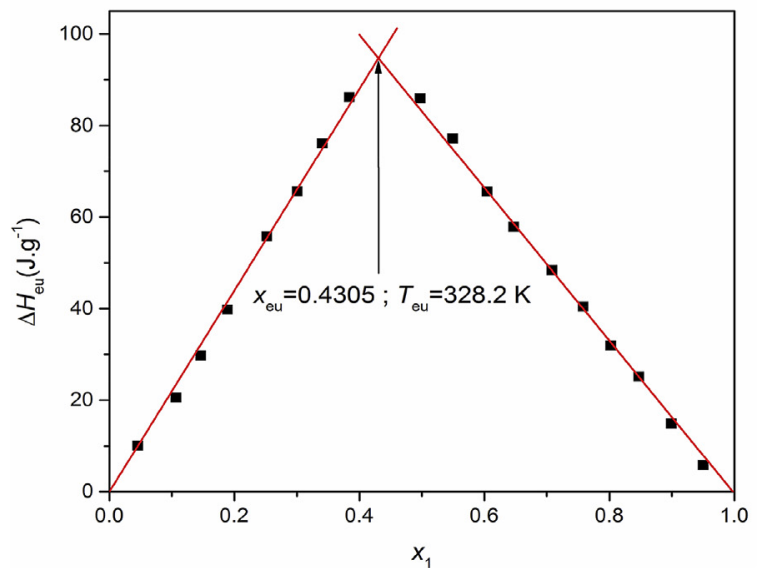

Fig. 3. Tamman plots for the studied binary systems (a) MENA + DPA, (b) MENA + ANA, (c) MENA+2-N-DPA, (d) MENA + EC.

Table 8

Comparison between the experimental and calculated coordinates values for the eutectics: $T_{\text {eu }}$ and $x_{1, \text { eu }}$ denote temperature and mole fraction, respectively.

\begin{tabular}{|c|c|c|c|c|}
\hline \multirow[t]{2}{*}{ System } & \multicolumn{2}{|l|}{$x_{1, \mathrm{eu}}$} & \multicolumn{2}{|l|}{$T_{\mathrm{eu}}(\mathrm{K})$} \\
\hline & $\operatorname{Exp}^{\mathrm{a}}$. & Cal. & $\operatorname{Exp}^{\mathrm{a}}$. & Cal. \\
\hline MENA (1) + DPA (2) & 0.3129 & $\begin{array}{l}0.2907^{b} \\
0.2766^{\mathrm{c}} \\
0.2588^{\mathrm{d}}\end{array}$ & 313.7 & $\begin{array}{l}314.6^{\mathrm{b}} \\
309.9^{\mathrm{c}} \\
312.6^{\mathrm{d}}\end{array}$ \\
\hline $\operatorname{MENA}(1)+$ ANA (2) & 0.6688 & $\begin{array}{l}0.6668^{b} \\
0.6695^{c} \\
0.5900^{d}\end{array}$ & 345.1 & $\begin{array}{l}345.8^{\mathrm{b}} \\
346.0^{\mathrm{c}} \\
339.3^{\mathrm{d}}\end{array}$ \\
\hline MENA (1) + 2-N-DPA (2) & 0.3905 & $\begin{array}{l}0.3635^{b} \\
0.3844^{\mathrm{c}} \\
0.4059^{\mathrm{d}}\end{array}$ & 332.0 & $\begin{array}{l}335.1^{\mathrm{b}} \\
335.0^{\mathrm{c}} \\
326.7^{\mathrm{d}}\end{array}$ \\
\hline MENA (1) + EC (2) & 0.4305 & $\begin{array}{l}0.4200^{b} \\
0.4433^{c} \\
0.4236^{d}\end{array}$ & 328.2 & $\begin{array}{l}332.4^{\mathrm{b}} \\
332.3^{\mathrm{c}} \\
328.1^{\mathrm{d}}\end{array}$ \\
\hline
\end{tabular}

a Standard uncertainties $u$ are: $u(x)= \pm 0.0005, u\left(T_{\mathrm{eu}}\right)= \pm 0.4 \mathrm{~K}, u(p)=0.05 \mathrm{kPa}$.

b Calculated by Wilson.

c Calculated by NRTL.

${ }^{\mathrm{d}}$ Assuming ideality.

and the correlation of the SLE data have been carried out by two local compositions models, namely Wilson and NRTL [34]. A brief presentation of the two thermodynamics models used in this work is reported in the SM.

The unknown model parameters were estimated applying the
Table 9

Quality factors values for the studied systems.

\begin{tabular}{|c|c|c|c|c|c|c|c|}
\hline MENA + DPA & Exp. (pure) & From SLE & $\Delta$ & \multicolumn{3}{|c|}{$\begin{array}{l}\text { Quality } \\
\text { factors }\end{array}$} & $Q_{S L E}$ \\
\hline Tf1/K & 358.9 & 358.6 & 0.3 & $\mathrm{~F} 1$ & 1.0 & $* 0.25$ & 0.859 \\
\hline $\mathrm{Tf} 2 / \mathrm{K}$ & 325.6 & 325.8 & 0.2 & $\mathrm{~F} 2$ & 1.0 & $* 0.25$ & \\
\hline Slope 1 & 0.0255 & 0.0316 & 0.2404 & F3 & 0.8320 & $* 0.25$ & \\
\hline Slope 2 & 0.0221 & 0.0295 & 0.3316 & $\mathrm{~F} 4$ & 0.6031 & $* 0.25$ & \\
\hline MENA + ANA & Exp. (pure) & From SLE & $\Delta$ & \multicolumn{3}{|c|}{$\begin{array}{l}\text { Quality } \\
\text { factors }\end{array}$} & $\mathrm{Q}_{\mathrm{SLE}}$ \\
\hline $\mathrm{Tf} 1 / \mathrm{K}$ & 358.9 & 358.6 & 0.3 & $\mathrm{~F} 1$ & 1.0 & $* 0.25$ & 0.943 \\
\hline $\mathrm{Tf} 2 / \mathrm{K}$ & 386.3 & 386.5 & 0.2 & $\mathrm{~F} 2$ & 1.0 & $* 0.25$ & \\
\hline Slope 1 & 0.0255 & 0.0321 & 0.2584 & F3 & 0.7739 & $* 0.25$ & \\
\hline Slope 2 & 0.0167 & 0.0179 & 0.0717 & $\mathrm{~F} 4$ & 1.0000 & $* 0.25$ & \\
\hline MENA+2-N-DPA & Exp. (pure) & From SLE & $\Delta$ & \multicolumn{3}{|c|}{$\begin{array}{l}\text { Quality } \\
\text { factors }\end{array}$} & $\mathrm{Q}_{\mathrm{SLE}}$ \\
\hline $\mathrm{Tf} 1 / \mathrm{K}$ & 358.9 & 359.1 & 0.2 & $\mathrm{~F} 1$ & 1.0 & $* 0.25$ & 0.794 \\
\hline $\mathrm{Tf} 2 / \mathrm{K}$ & 347.9 & 348.1 & 0.2 & $\mathrm{~F} 2$ & 1.0 & $* 0.25$ & \\
\hline Slope 1 & 0.0255 & 0.0339 & 0.3290 & F3 & 0.6078 & $* 0.25$ & \\
\hline Slope 2 & 0.0236 & 0.0318 & 0.3515 & $\mathrm{~F} 4$ & 0.5690 & ${ }^{*} 0.25$ & \\
\hline $\mathrm{MENA}+\mathrm{EC}$ & Exp. (pure) & From SLE & $\Delta$ & \multicolumn{3}{|c|}{$\begin{array}{l}\text { Quality } \\
\text { factors }\end{array}$} & $Q_{S L E}$ \\
\hline $\mathrm{Tf} 1 / \mathrm{K}$ & 358.9 & 358.9 & 0.0 & $\mathrm{~F} 1$ & 1.0 & ${ }^{*} 0.25$ & 0.703 \\
\hline $\mathrm{Tf} 2 / \mathrm{K}$ & 345.7 & 345.8 & 0.1 & $\mathrm{~F} 2$ & 1.0 & $* 0.25$ & \\
\hline Slope 1 & 0.0255 & 0.0343 & 0.3451 & F3 & 0.5795 & ${ }^{*} 0.25$ & \\
\hline Slope 2 & 0.0297 & 0.0552 & 0.8589 & $\mathrm{~F} 4$ & 0.2329 & ${ }^{*} 0.25$ & \\
\hline
\end{tabular}


Table 10

Correlation of the SLE data of the four binary mixtures by Wilson and NRTL models: parameters and deviations.

\begin{tabular}{|c|c|c|c|c|c|c|c|}
\hline \multirow[t]{3}{*}{ System } & \multicolumn{4}{|c|}{ Parameters (J.mol $\left.{ }^{-1}\right)$} & \multicolumn{3}{|c|}{ Deviation $\sigma^{\mathrm{a}}(\mathrm{K})$} \\
\hline & Wilson & Wilson & NRTL & NRTL & Wilson & NRTL & Ideal \\
\hline & $\lambda_{12}-\lambda_{11}$ & $\lambda_{21}-\lambda_{22}$ & $\mathrm{~g}_{12}-\mathrm{g}_{11}$ & $\mathrm{~g}_{21-} \mathrm{g}_{22}$ & & & \\
\hline $\operatorname{MENA}(1)+\operatorname{DPA}(2)$ & 2258.72 & -469.57 & 3006.63 & -1027.16 & 1.77 & 2.10 & 2.38 \\
\hline $\operatorname{MENA}(1)+\mathrm{ANA}(2)$ & 2948.59 & -235.86 & -351.75 & 3003.15 & 1.37 & 1.40 & 5.49 \\
\hline MENA(1)+2-N-DPA & 2246.58 & 854.27 & -247.11 & 3381.86 & 1.92 & 1.88 & 4.14 \\
\hline $\operatorname{MENA}(1)+\mathrm{EC}(2)$ & 4061.28 & -1891.32 & -2149.04 & 5270.42 & 2.22 & 2.29 & 2.77 \\
\hline
\end{tabular}

a according to Eq. (4).

Nelder-Mead simplex method to minimize the following objective function $\mathrm{F}_{0}$ [37]:

$\mathrm{F}_{0}=\sum_{\mathrm{i}=1}^{\mathrm{n}}\left\{T_{\mathrm{i}}^{\mathrm{exp}}-T_{\mathrm{i}}^{\mathrm{cal}}\left(x_{1 \mathrm{i}}, \mathrm{A}_{1}, \mathrm{~A}_{2}\right)\right\}^{2}$

where $\mathrm{n}$ is the number of experimental points, $T_{\mathrm{i}}^{\mathrm{exp}}$ and $T_{\mathrm{i}}^{\mathrm{cal}}$ stand, respectively, for the experimental and the calculated equilibrium temperatures at a given concentration $x_{1 \mathrm{i}}$, and $\mathrm{A}_{1}, \mathrm{~A}_{2}$ are the two adjustable parameters of each model.

The Nelder-Mead simplex algorithm, used for the optimization of deterministic problems, found a large acceptance and use in the field of chemistry and chemical engineering. The detailed NelderMead simplex algorithm can be found elsewhere $[38,39]$.

(a)

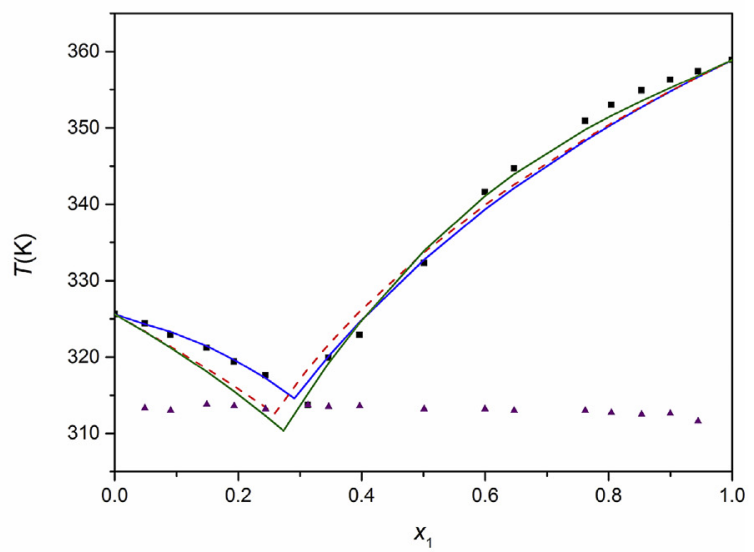

(b)

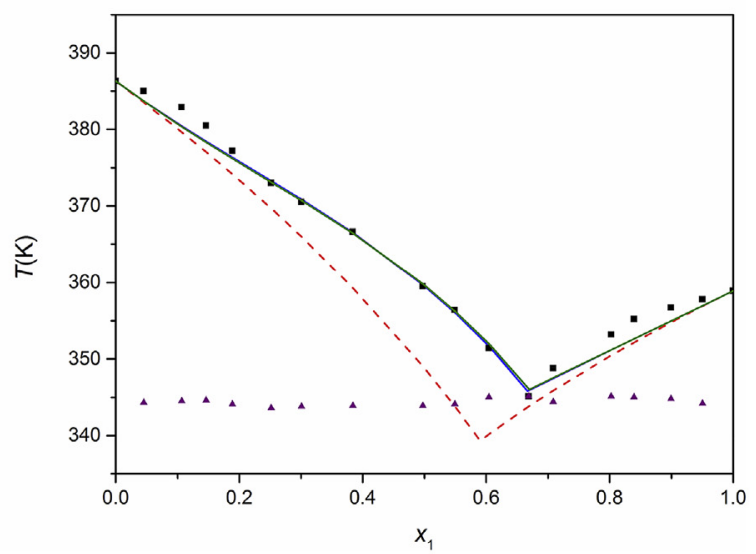

The root mean square deviation $\left(\sigma_{\mathrm{T}}\right)$ used to evaluate the quality of the fit is defined as:

$\sigma_{\mathrm{T}}=\left[\sum_{\mathrm{i}=1}^{\mathrm{n}} \frac{\left(T_{\mathrm{i}}^{\mathrm{exp}}-T_{\mathrm{i}}^{\mathrm{cal}}\right)^{2}}{\mathrm{n}-\mathrm{m}}\right]^{1 / 2}$

being $m$ the number of the adjustable parameters for each model, which is equal to 2 in our case. Effectively, the NRTL model encloses three parameters, however, the reduction of experimental data for a large number of binary systems allowed verifying that the nonrandomness parameter $\left(\alpha_{12}\right)$ ranges from about 0.20 to 0.47 . A typical choice is $\alpha_{12}=0.3[11,34,40]$ here adopted.

(c)

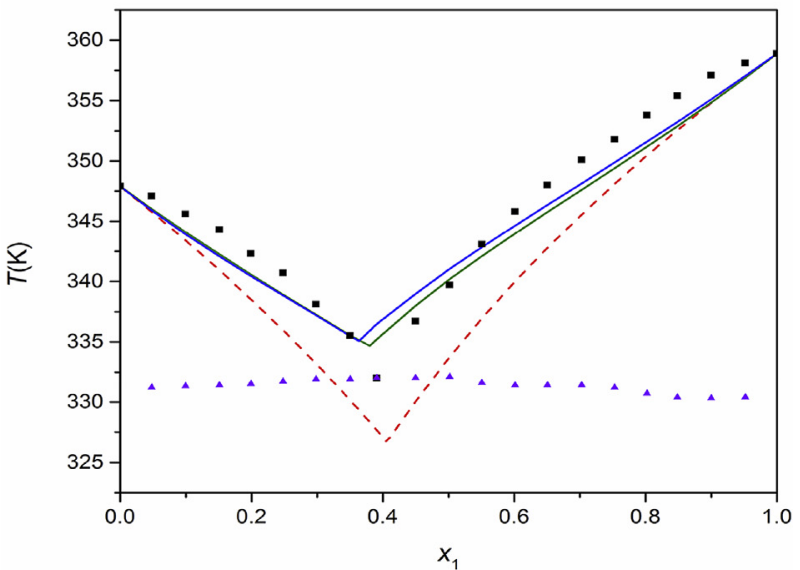

(d)

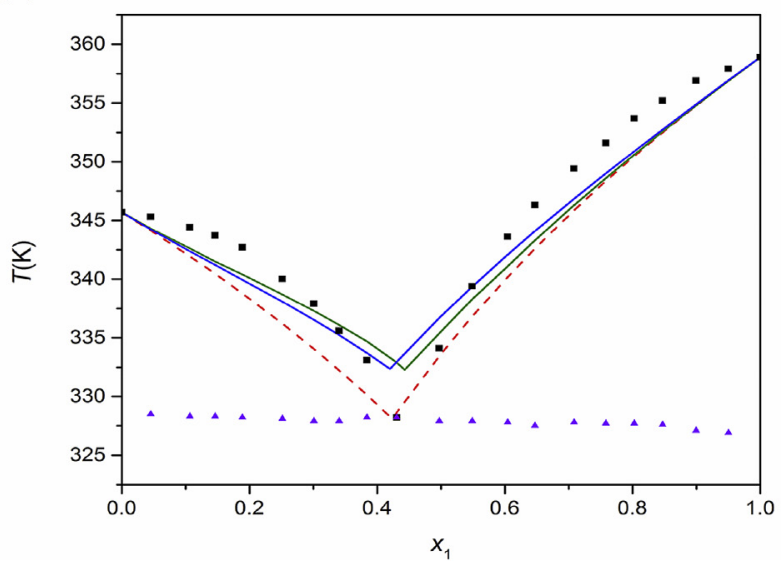

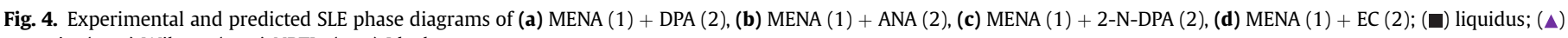
eutectic; (—) Wilson; (-) NRTL; (- - -) Ideal. 
Table 10 summarizes the estimated parameters as well as the root-mean-square deviations. A comparison between the experimental data and the correlation results including the liquidus line assuming ideality is presented in Fig. 4. The two models calculate equilibrium temperatures similarly with an average standard deviation (4systems) for Wilson and NRTL of $1.82 \mathrm{~K}$ and $1.92 \mathrm{~K}$, respectively. As observed before [2], except for S3, Wilson model gives a slightly better description than the NRTL equation. The selection of the liquidus temperature to be the onset, peak or endset temperature affects, naturally, the modeling results.

As shown in Table 8, the difference between the experimental eutectic temperature $T_{\text {eu }}$ and the eutectic mole fraction $x_{\text {eu }}$ found using the Tamman plot and those calculated by Wilson and NRTL equations are reasonable.

\subsubsection{Excess thermodynamic functions}

The measure and the nature of the molecular interactions occurring in a binary mixture as well as the deviation from the ideal behavior can be well highlighted by evaluating the excess thermodynamic properties, namely, excess Gibbs energy, enthalpy, and entropy.

Based on the $G^{\mathrm{E}}$ expression in the two semi-empirical models, the Gibbs-Duhem relation (Eq. (5)) is used to evaluate the excess enthalpy of our systems:

(a)

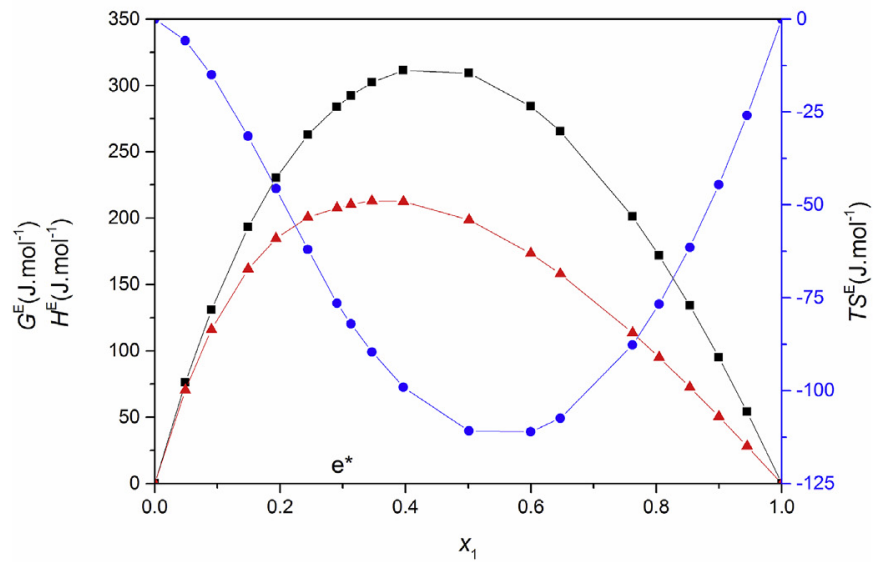

(b)

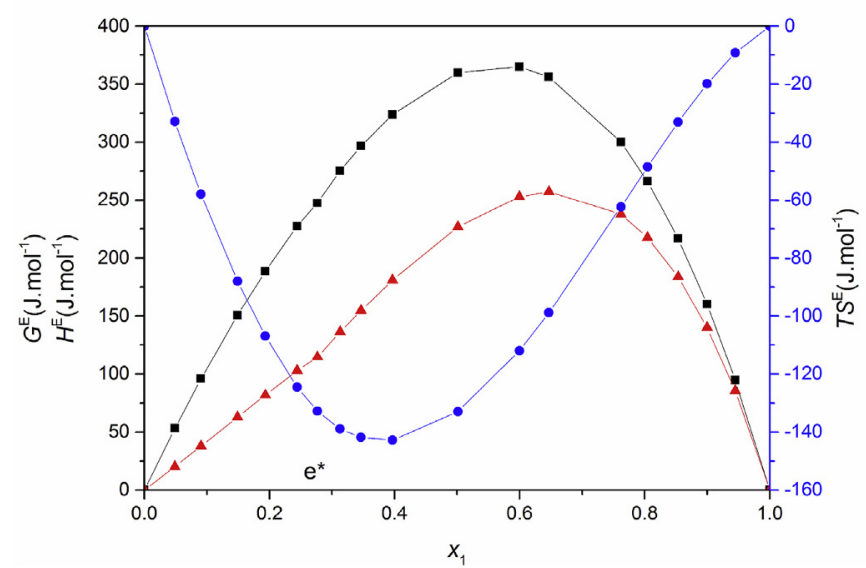

Fig. 5. Excess thermodynamic functions for MENA(1) + DPA (2) system, (a) Wilson, (b) NRTL: (ם) $G^{\mathrm{E}},(\boldsymbol{\Delta}) H^{\mathrm{E}},(\bullet) T S^{\mathrm{E}}$. (e* is the model estimated eutectic).
$H^{\mathrm{E}}=-R T^{2}\left[\frac{\partial\left(G^{\mathrm{E}} / R T\right)}{\partial T}\right]_{x_{1}, P}$

Furthermore, the following equation is used to estimate the excess entropy:

$T S^{\mathrm{E}}=H^{\mathrm{E}}-G^{\mathrm{E}}$

The values of the excess thermodynamic properties for all the studied systems, computed using the temperature values obtained by Wilson and NRTL models, are reported in Tables S1-S4 of the supporting materials. Likewise, the obtained values are presented in Figs. 5-8 with respect to the mole fraction composition. It is clearly shown that the two equations provide values highly similar for qualitative and quantitative analysis.

In the current study, it is not possible to observe a global maximum, or minimum, of the excess properties at the eutectic point, inversely to what has been repeatedly spread in the literature $[41,42]$, where for those functions mathematical extremes had been proposed exactly at the eutectic mixture. However, it should be noted that the excess values at the eutectic are, in general, close to the observed minima or maxima which can most probably be attributed to a result of the minimum temperature value at the

(a)

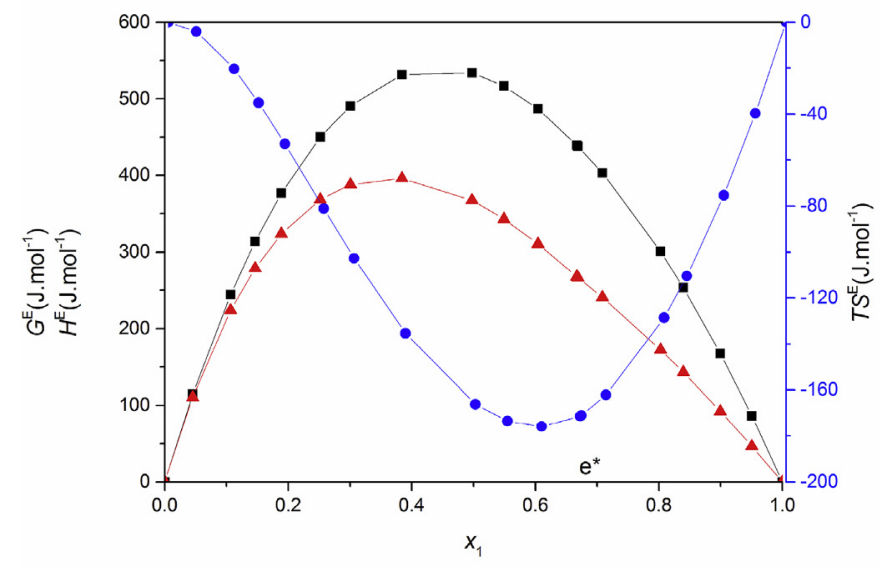

(b)

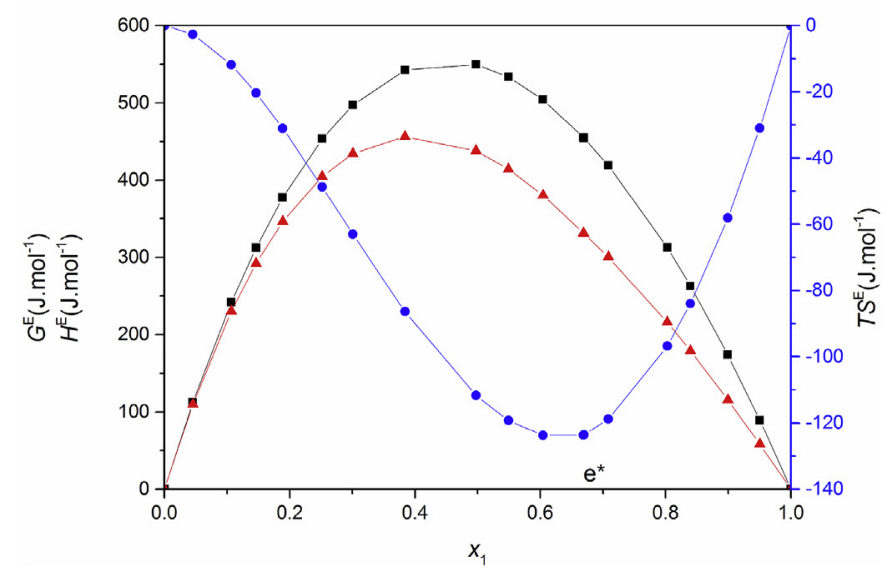

Fig. 6. Excess thermodynamic functions for MENA(1) + ANA (2) system, (a) Wilson, (b) NRTL: (ם) $G^{\mathrm{E}},(\boldsymbol{\Delta}) H^{\mathrm{E}},(\bullet) T S^{\mathrm{E}}$. (e* is the model estimated eutectic). 
(a)

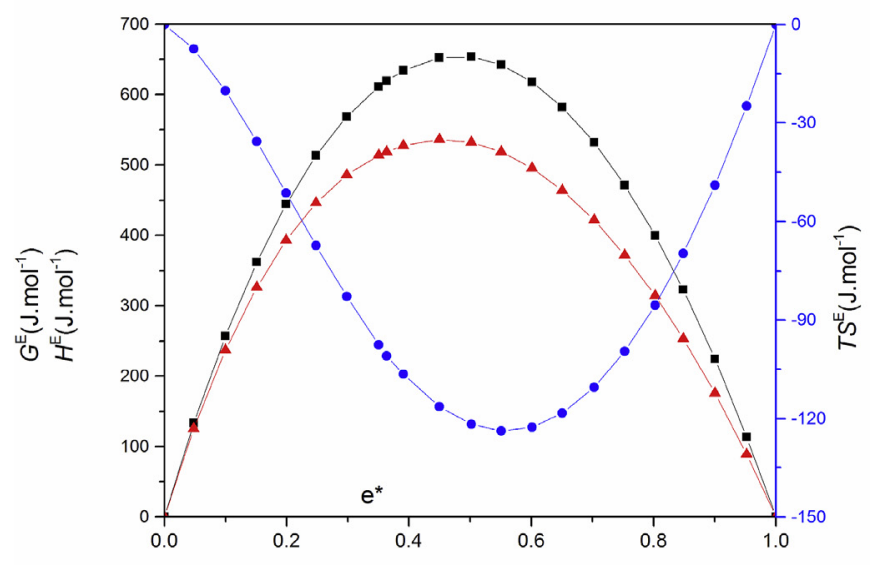

(b)

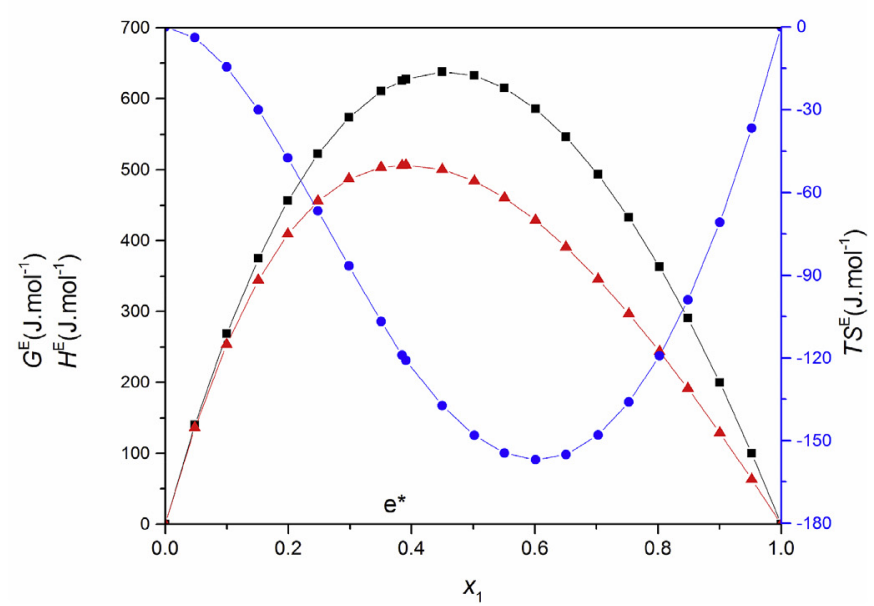

Fig. 7. Excess thermodynamic functions for MENA(1) + 2-N-DPA (2) system, (a) Wilson, (b) NRTL: (口) $G^{\mathrm{E}},(\mathbf{\Delta}) H^{\mathrm{E}},(\bullet) T S^{\mathrm{E}}$. (e* is the model estimated eutectic).

eutectic.

For all investigated systems, the application of both models resulted in positive values of excess Gibbs energy and enthalpy, which is quite common for liquid mixtures, while the excess entropy values are negative for S1 (MENA + DPA), S2 (MENA + ANA), and S3 (MENA+2-N-DPA) and positive for S4 (MENA + EC).

The nature and the intensity of intermolecular attractions between pairs of dissimilar species on one hand, and pairs of like species, on the other hand, can be directly elucidated based on the recorded differences in the sign and the magnitude of the excess Gibbs energy [43-45]. As shown in Fig. 4, all the studied systems present a positive deviation from ideality, which is more pronounced for S2 and S3. $G^{\mathrm{E}} / R T$ and $H^{\mathrm{E}} / R T$ are positive while $S^{\mathrm{E}} / R$ is negative (systems S1 to S3). This is a typical behavior for mixtures containing a polar and associative compound, with non-polar compounds. That means that intermolecular attractions between pairs of similar species are predominant.

Despite the steric hindrance due to the bulky phenyl and alkyl groups in S2 and S3, respectively, both molecules in those systems present a hydrogen bond donor and a similar number of hydrogen bond acceptors, which can promote self-association, more strongly in 2-N-DPA and ANA because of the closeness between the electronegative atoms and the positively charged hydrogen atom. For (a)

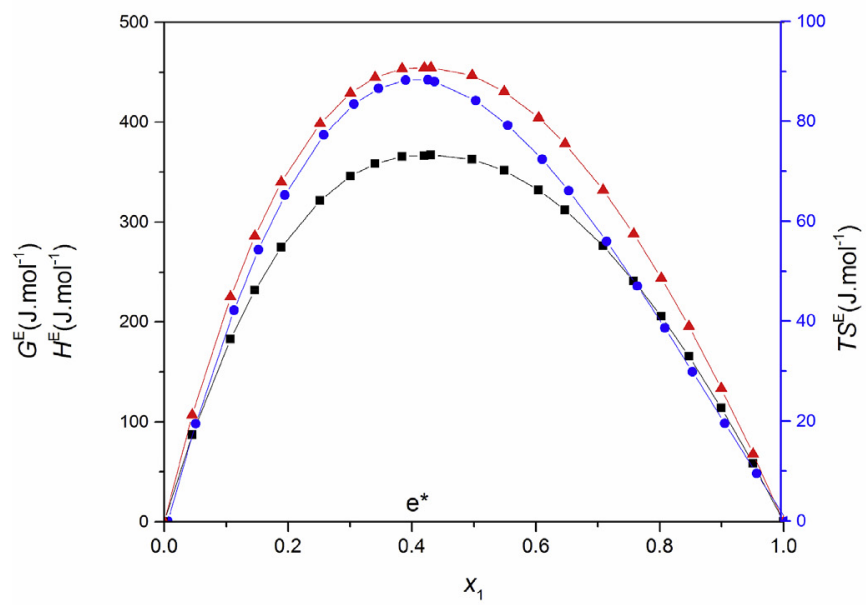

(b)

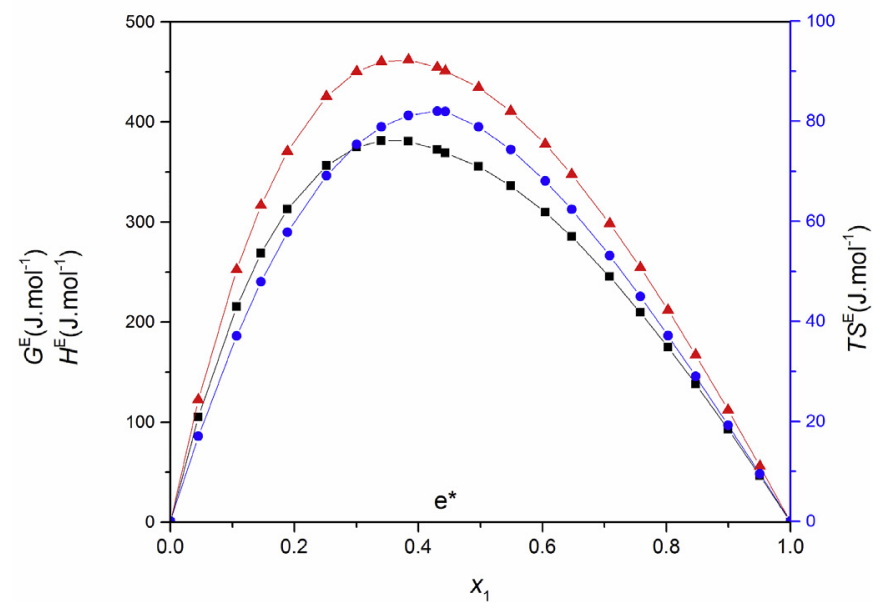

Fig. 8. Excess thermodynamic functions for MENA(1) + EC (2) system, (a) Wilson, (b) NRTL: $(\boldsymbol{\square}) G^{\mathrm{E}},(\boldsymbol{\Delta}) H^{\mathrm{E}},(\bullet) T S^{\mathrm{E}}$. (e* is the model estimated eutectic).

those particular systems MENA+2-N-DPA and MENA + ANA conjointly with the first system MENA + DPA, the excess entropy values calculated by both models are found negative suggesting that restructuring takes place owing to interactions promoting clustering within the solution. For system S4 (MENA + EC), even if closer to ideality, all the properties are positive, and it is clear to conclude that the enthalpic effect is dominant. The positive excess entropy in system S4 can be easily connected to the differences in the volumes of the molecules.

\section{2. $X$-ray diffraction analysis $(X R D)$}

Plots (1)-(4) in Fig. 9 present the X-ray diffraction diagrams for the eutectic compositions of the four studied systems conjointly with those of the pure components. Furthermore, EXPO 2014 software [46] was used to evaluate the Bragg angles, the interreticular distances and the Miller indices of the eutectics, as well as the pure stabilizers under study. The XRD data are reported in Tables S5-S13 of the SM.

It was found that pure MENA crystallizes in an orthorhombic system, DPA and ANA crystallize both in monoclinic systems, while 2-N-DPA and EC in a triclinic configuration. 
(1)

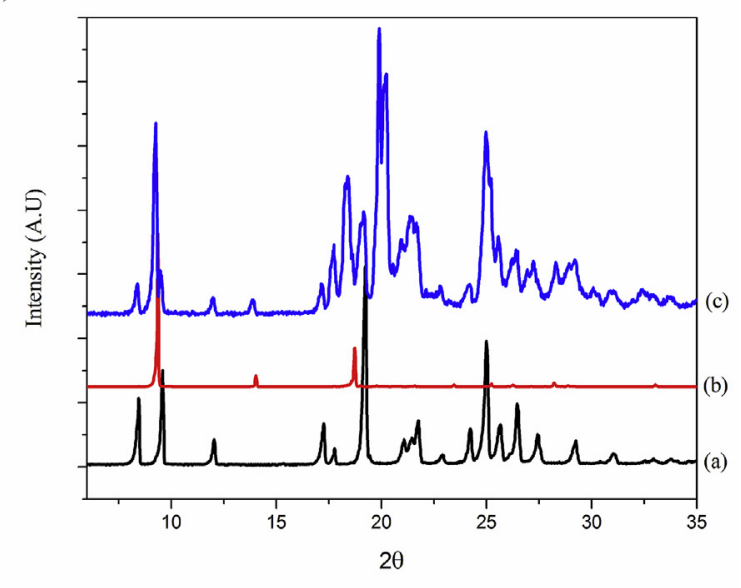

(2)

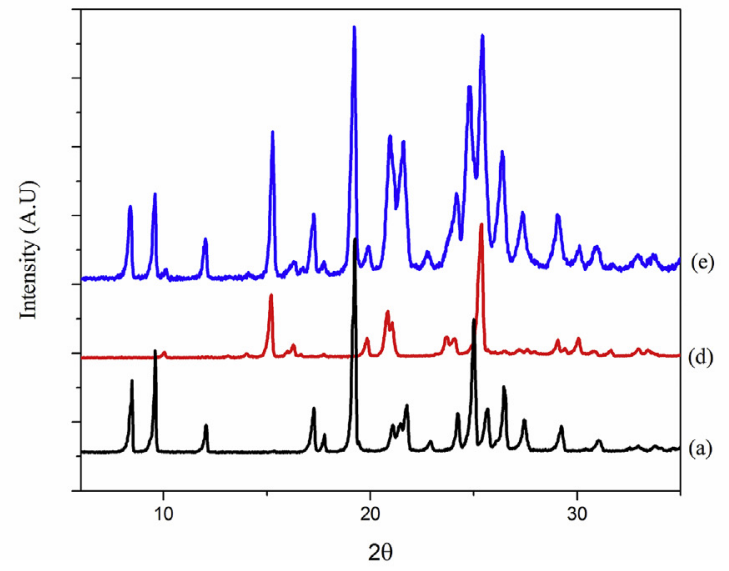

(3)

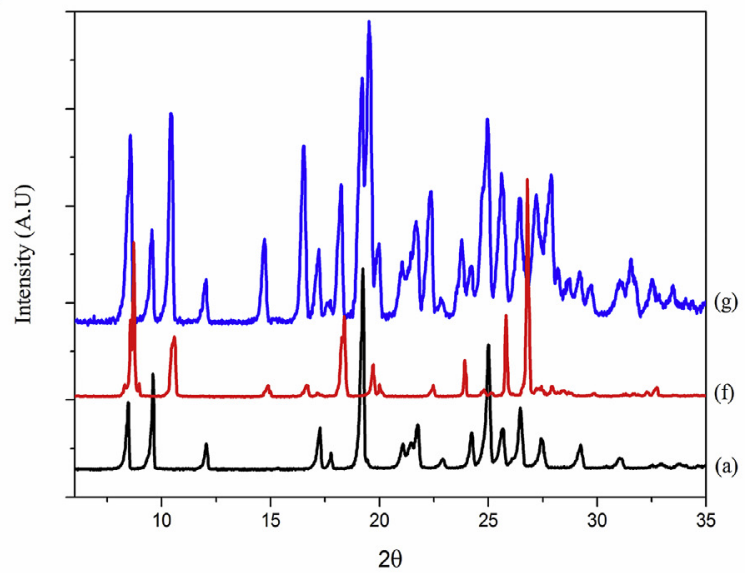

(4)

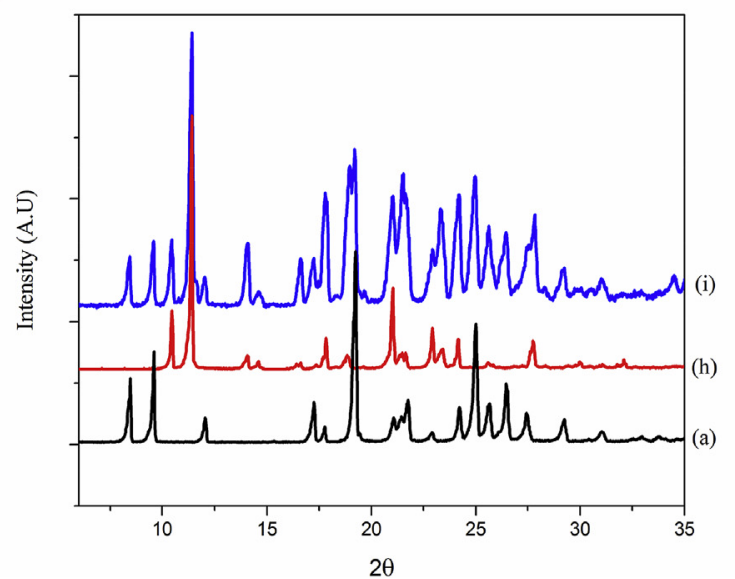

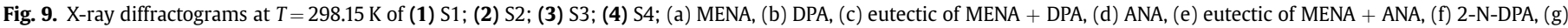
eutectic of MENA+2-N-DPA, (h) EC, (i) eutectic of MENA + EC.

From Fig. 9, it can be inferred that pure compounds crystallize separately in their own crystals as it should be for eutectics. In fact, the X-ray patterns of all eutectics gather all the peaks of their respective pure compounds suggesting thereby that the studied eutectics are mechanical systems of two components [47]. Moreover, the XRD data and diffractograms of pure compounds, as well as eutectics, reported in Tables S5-S13 and Fig. 9, respectively, showed differences in the interplanar distances (evaluated by EXPO software) and the relative intensities of pure compounds peaks compared to those of their respective eutectics which can be explained by the subsistence of weak molecular interactions between the components in the eutectics [48]. This behavior can be explained by the dominant effect of the molecules self-association with weaker interactions between dissimilar components corroborating the positive deviation from ideality recorded for all the investigated systems.

\section{Conclusions}

Phase equilibria for four binary mixtures of nitrate esters based energetic materials stabilizers have been investigated to predict their evolution and to check their thermodynamic behavior with respect to temperature changes. Consistent SLE data have been obtained using DSC technique. The investigated binary mixtures form simple eutectics. The results gathered, demonstrate that the melting temperature of the eutectic point must be high enough before the incorporation of such mixtures of stabilizers in the energetic materials, in order to avoid stability issues.

The Wilson and NRTL models correlate accurately the binary SLE data and are suitable to describe the solid-liquid phase diagrams for the studied binary mixtures of organic stabilizers. The Wilson model showed slightly better results presenting temperature root mean square deviations lower than $2.22 \mathrm{~K}$.

The calculation of the excess thermodynamic functions contributes to a better understanding of the type and the intensity of the molecular interactions occurring in the mixture. Excess properties at the eutectic coordinates do not present a mathematic extreme contrary to what has been spreading often in the literature. The obtained results for the excess thermodynamic functions suggest the existence of molecular interactions in the solutions, which are most probably due to self-association.

Molecular interactions studies by means of XRD analysis show the existence of weak interactions between the components for the obtained eutectics and suggest that they are mechanical mixtures of two components, supporting the excess thermodynamic functions trends.

According to the thermodynamic and molecular interaction investigations performed in this study, the eutectic composition of binary mixtures of organic stabilizers can be safely incorporated into the nitrate esters-based energetic materials formulations. 


\section{Acknowledgments}

The authors are grateful for the financial support of this research from Ecole Militaire Polytechnique (Doctoral Training Program) and Project POCI-01-0145-FEDER-006984 (Ref. FCT UID/EQU/50020/ 2019) - Associate Laboratory LSRE-LCM - funded by European Regional Development Fund (ERDF) through COMPETE2020 Programa Operacional Competitividade e Internacionalização (POCI) - and by national funds through FCT - Fundacão para a Ciência e a Tecnologia I.P.

\section{Appendix A. Supplementary data}

Supplementary data to this article can be found online at https://doi.org/10.1016/j.fluid.2019.06.021.

\section{References}

[1] D. Trache, A.F. Tarchoun, Stabilizers for nitrate ester-based energetic materials and their mechanism of action: a state-of-the-art review, J. Mater. Sci. 53 (2018) 100-123.

[2] S. Chelouche, D. Trache, C.M. Neves, S.P. Pinho, K. Khimeche, M. Benziane Solid + liquid equilibria and molecular structure studies of binary mixtures for nitrate ester's stabilizers: measurement and modeling, Thermochim. Acta 666 (2018) 197-207.

[3] P. Satyaprasad, M.P.R. Sharma, A. Richarya, A.R. Ranjit, B.S. Chandran, Missile propulsion systems, in: Aerospace Materials and Material Technologies, Springer, 2017, pp. 305-330.

[4] A. Dejeaifve, R. Dobson, Tocopherol stabilisers for nitrocellulose-based propellants, in: Google Patents, 2018.

[5] R. Baetens, B.P. Jelle, A. Gustavsen, Phase change materials for building applications: a state-of-the-art review, Energy Build. 42 (2010) 1361-1368.

[6] P. Liu, J.-W. Hao, L.-P. Mo, Z.-H. Zhang, Recent advances in the application of deep eutectic solvents as sustainable media as well as catalysts in organic reactions, RSC Adv. 5 (2015) 48675-48704.

[7] D. Trache, K. Khimeche, M. Benziane, A. Dahmani, Solid-liquid phase equilibria for binary mixtures of propellant's stabilizers, J. Therm. Anal. Calorim. 112 (2013) 215-222.

[8] D. Trache, K. Khimeche, A. Dahmani, Study of (solid-liquid) phase equilibria for mixtures of energetic material stabilizers and prediction for their subsequent performance, Int. J. Thermophys. 34 (2013) 226-239.

[9] J.D. Gibson, Stabilizers for cross-linked composite modified double base propellants, in, US Patent 5,387,295, 1995.

[10] W. Acree Jr. J.S. Chickos, Phase transition enthalpy measurements of organic and organometallic compounds and ionic liquids. Sublimation, vaporization, and fusion enthalpies from 1880 to 2015. Part 2. C11-C192, J. Phys. Chem. Ref. Data 46 (2017), 013104.

[11] D. Trache, K. Khimeche, R. Benelmir, A. Dahmani, DSC measurement and prediction of phase diagrams for binary mixtures of energetic materials' stabilizers, Thermochim. Acta 565 (2013) 8-16.

[12] W.E. Acree, Thermodynamic properties of organic compounds: enthalpy of fusion and melting point temperature compilation, Thermochim. Acta 189 (1991) 37-56.

[13] W.M. Haynes, D.R. Lide, CRC Handbook of Physics and Chemistry, CRC Press, USA, 2009.

[14] D. Lide, D.R., CRC Handbook of Chemistry and Physics, CRC Press, Boca Raton, FL, itd, 2003-2004.

[15] A.O. Surov, I.V. Terekhova, A. Bauer-Brandl, G.L. Perlovich, Thermodynamic and structural aspects of some fenamate molecular crystals, Cryst. Growth Des. 9 (2009) 3265-3272.

[16] S. Chelouche, D. Trache, S.P. Pinho, K. Khimeche, A. Mezroua, M. Benziane, Solid-liquid phase equilibria, molecular interaction and microstructural studies on (N-(2-ethanol)-p-nitroaniline + $\mathrm{N}$-(2-acetoxyethyl)-p-nitroaniline) binary mixtures, Int. J. Thermophys. 39 (2018) 129.

[17] D.R. Lide, CRC Handbook of Chemistry and Physics, CRC, Boca Raton, 2012.

[18] A. Książczak, T. Książczak, M. Ostrowski, Intermolecular interactions and phase equilibria in nitrocellulose-s-diethyldiphenylurea system, J. Therm. Anal. Calorim. 74 (2003) 575-581.

[19] M.H. Keshavarz, A.R. Akbarzadeh, R. Rahimi, M. Jafari, M. Pasandideh, R. Sadeghi, A reliable method for prediction of enthalpy of fusion in energetic materials using their molecular structures, Fluid Phase Equilib. 427 (2016) 46-55.

[20] A. Jain, G. Yang, S.H. Yalkowsky, Estimation of melting points of organic compounds, Ind. Eng. Chem. Res. 43 (2004) 7618-7621.

[21] D. Mackay, W.-Y. Shiu, K.-C. Ma, S.C. Lee, Handbook of Physical-Chemical Properties and Environmental Fate for Organic Chemicals, CRC press, 2006.
[22] R. Meyer, J. Köhler, A. Homburg, Explosives, in: Wiley-VCH Verlag GmbH, Weinheim, Sixth Completely Revised Edition, 2007.

[23] E. Baum, Chemical Property Estimation: Theory and Application, CRC Press, 1997.

[24] L.P.S. Silva, D. Dalmazzone, M. Stambouli, A.-L. Lesort, P. Arpentinier, A. Trueba, W. Fürst, Phase equilibria of semi-clathrate hydrates of tetra-nbutyl phosphonium bromide at atmospheric pressure and in presence of CH4 and CO2+ CH4, Fluid Phase Equilib. 413 (2016) 28-35.

[25] G. Ma, J. Sun, S. Xie, Z. Wang, Y. Jing, Y. Jia, Solid-liquid phase equilibria of stearic acid and dicarboxylic acids binary mixtures as low temperature thermal energy storage materials, J. Chem. Thermodyn. 120 (2018) 60-71.

[26] A. Abdelaziz, D. Zaitsau, T. Mukhametzyanov, B. Solomonov, P. Cebe, S. Verevkin, C. Schick, Melting temperature and heat of fusion of cytosine revealed from fast scanning calorimetry, Thermochim. Acta 657 (2017) 47-55.

[27] Y. Corvis, A. Spasojević-de Biré, C. Alzina, N. Guiblin, P. Espeau, Kinetics of the (solid+ solid) transformations for the piracetam trimorphic system: incidence on the construction of the $\mathrm{p}-\mathrm{T}$ equilibrium phase diagram, J. Chem. Thermodyn. 97 (2016) 167-172.

[28] J.H. Oakley, T.J. Hughes, B.F. Graham, K.N. Marsh, E.F. May, Determination of melting temperatures in hydrocarbon mixtures by differential scanning calorimetry, J. Chem. Thermodyn. 108 (2017) 59-70.

[29] T. Kousksou, A. Jamil, T. El Rhafiki, Y. Zeraouli, Paraffin wax mixtures as phase change materials, Sol. Energy Mater. Sol. Cell. 94 (2010) 2158-2165.

[30] H. Takiyama, H. Suzuki, H. Uchida, M. Matsuoka, Determination of solid-liquid phase equilibria by using measured DSC curves, Fluid Phase Equilib. 194 (2002) 1107-1117.

[31] C.-C. Huang, Y.-P. Chen, Measurements and model prediction of the solid-liquid equilibria of organic binary mixtures, Chem. Eng. Sci. 55 (2000) 3175-3185.

[32] J.W. Kang, V. Diky, R.D. Chirico, J.W. Magee, C.D. Muzny, A.F. Kazakov, K. Kroenlein, M. Frenkel, Algorithmic framework for quality assessment of phase equilibrium data, J. Chem. Eng. Data 59 (2014) 2283-2293.

[33] U. Domańska, J. Łachwa, Thermodynamics of binary mixtures of N-methyl-2pyrrolidinone and ketone. Experimental results and modelling of the (solid+ liquid) equilibrium and the (vapour+ liquid) equilibrium. The modified UNIFAC (Do) model characterization, J. Chem. Thermodyn. 37 (2005) $692-704$.

[34] J.M. Prausnitz, R.N. Lichtenthaler, E.G. de Azevedo, Molecular Thermodynamics of Fluid-phase Equilibria, Pearson Education, 1998.

[35] A. Iddaoudi, N. Selhaoui, M.A. Amar, K. Mahdouk, A. Aharoune, L. Bouirden, Thermodynamic description of the Lu-Pb binary system, J. Therm. Anal. Calorim. 110 (2012) 923-928.

[36] R. Reddi, V.K. Satuluri, U. Rai, R. Rai, Thermal, physicochemical and microstructural studies of binary organic eutectic systems, J. Therm. Anal. Calorim. 107 (2012) 377-385.

[37] J.A. Nelder, R. Mead, A simplex method for function minimization, Comput. J. 7 (1965) 308-313.

[38] J.C. Lagarias, J.A. Reeds, M.H. Wright, P.E. Wright, Convergence properties of the Nelder-Mead simplex method in low dimensions, in: SIAM Journal on Optimization, 1998, pp. 112-147.

[39] N. Tippayawannakorn, J. Pichitlamken, Nelder-Mead method with local selection using memory for discrete stochastic optimization, Thail. Stat. 14 (2016) 63-81.

[40] D. Trache, K. Khimeche, Study on the influence of ageing on thermal decomposition of double-base propellants and prediction of their in-use time, Fire Mater. 37 (2013) 328-336.

[41] B. Sharma, S. Gupta, S. Tandon, R. Kant, Physico-mechanical properties of naphthalene-acenaphthene eutectic system by different modes of solidification, Mater. Chem. Phys. 111 (2008) 423-430.

[42] P. Gupta, T. Agrawal, S.S. Das, N.B. Singh, Phase equilibria and molecular interaction studies on (naphthols + vanillin) systems, J. Chem. Thermodyn. 48 (2012) 291-299.

[43] P. Navia, J. Troncoso, L. Romaní, Excess magnitudes for ionic liquid binary mixtures with a common ion, J. Chem. Eng. Data 52 (2007) 1369-1374.

[44] M. Okuniewski, K. Paduszynski, U. Domanska, Thermodynamic study of molecular interactions in eutectic mixtures containing camphene, J. Phys. Chem. B 120 (2016) 12928-12936.

[45] S.M. Nayeem, Investigation of molecular interactions \& prediction of calorimetric potentials of a binary liquid system at $\mathrm{T}=308.15 \mathrm{~K}$ : an insight from physicochemical parameters, Karbala Int. J. Mod. Sci. 3 (3) (2017) 176-184.

[46] A Altomare N. Corriero, C. Cuocci, A. Falcicchio, A. Moliterni, R Rizzi, EXPO software for solving crystal structures by powder diffraction data: methods and application, Cryst. Res. Technol. 50 (2015) 737-742.

[47] U. Rai, M. Singh, R. Rai, Some physicochemical studies on organic eutectics and inter-molecular compounds, J. Therm. Anal. Calorim. 130 (2017) 967-974.

[48] U. Rai, S. George, Physicochemical studies on organic eutectics and the 1: 1 addition compound: benzidine- $\alpha$-naphthol system, J. Mater. Sci. 27 (1992) $711-718$. 